\title{
Impact of winter storms on sediment erosion in the Rhone River prodelta and fate of sediment in the Gulf of Lions (North Western Mediterranean Sea)
}

\author{
François Dufois $^{\mathrm{a}, \mathrm{b}, \mathrm{c}, *}$, Romaric Verney ${ }^{\mathrm{b}}$, Pierre Le Hir ${ }^{\mathrm{b}}$, Franck Dumas ${ }^{\mathrm{b}}$, Sabine Charmasson ${ }^{\mathrm{c}}$ \\ ${ }^{a}$ CSIRO Marine and Atmospheric Research, Private Bag 5, Wembley WA 6913, Australia \\ ${ }^{b}$ IFREMER, Centre de Brest, BP 70, 29280 Plouzané, France \\ ${ }^{c}$ IRSN, Centre Ifremer, CS 30330, 83507 La Seyne sur Mer, France \\ *: Corresponding author : François Dufois, tel.: +61 893336535 ; email address : francois.dufois@csiro.au
}

\begin{abstract}
:
In this study a three-dimensional sediment transport model was developed. The model accounts for both current and wave forcing on the sediment and was implemented over the Gulf of Lions. A twoway nesting technique was used to focus on the Rhone River prodelta which is considered as a sink for riverine sediment. In addition, to understand the resuspension of trapped sediment over the Rhone prodelta, an in situ experiment, called SCOPE, was conducted during the winter 2007/2008. The experiment consisted of measuring hydro-sedimentary parameters using a mooring station comprising a current profiler (ADCP) and an altimeter (acoustic transducer) located in the eastern part of the Rhone prodelta. The three-dimensional transport model was validated using these data, and used to investigate the effect of sediment dynamics at the prodelta and Gulf of Lions scale. Both modelling and data analysis highlighted the impact of the two strong storms from the south-east which characterised the experimental period. Erosion of bed material (about $2 \mathrm{~cm}$ ) and an increase in suspended material (up to about $50-100 \mathrm{mg} / \mathrm{l}$ ) in the water were the result of each storm as recorded at the mooring station. The erosion capacity due to waves, combined with a strong current, due to both wind and wave forcing, resulted in strong south-westward export over the whole prodelta. Each storm was responsible for an off-prodelta export estimated at around $2.1 \mathrm{Mt}$. This study demonstrates that the Rhone River sediments trapped over the Rhone prodelta are subject to strong resuspension during episodic events.
\end{abstract}

\section{Highlights}

A 3D sediment transport model is developed. The hydro-sedimentary in situ SCOPE experiment is presented. The model is validated using the various in situ data. The impact of winter storms over the Rhone prodelta is assessed.

Keywords : Sediment transport ; Gulf of Lions ; Rhone prodelta ; 3D modelling ; ADCP ; ALTUS 


\section{Introduction}

Like many European river basins, the Rhone River basin covers populated, industrial and agricultural areas. In such environments, human activity often results in the introduction of pollutants into the riverine ecosystem. Some of these pollutants (heavy metals, radionuclides, etc.) have a high affinity for particulate matter which makes understanding particle behaviour over continental margins particularly important.

Among continental margin systems, river-dominated ocean margins have some of the highest sediment deposition rates of all marine systems (McKee et al., 2004). According to Walsh and Nittrouer (2009), the river-dominated continental margin of the Gulf of Lions (GoL), through which the Rhone River flows, is a proximal-accumulation-dominated system. In such environments characterised by a low tidal range and relatively low mean significant wave height (Walsh and Nittrouer, 2009), fine-grained sediments accumulate rapidly near the river mouth and the accumulation rate is greatly affected by flood events (Hossain et al., 2001). This is particularly true in the GoL where the Rhone River sediment discharge leads to the formation of a prodeltaic structure directly downstream from the river mouth (Roussiez et al., 2005). Up to now, extensive studies have focused on direct dispersion of suspended material from the Rhone river to the prodelta or to the shelf (e.g. Pauc, 1970; Got and Aloisi, 1990; Naudin et al., 1997; Arnoux-Chiavassa et al., 1999; Radakovitch et al., 1999; Thill et al., 2001; Miralles et al., 2006). However, sediments are not always directly dispersed. They can be stored temporarily in prodeltas before being resuspended and transported further away. To better understand the sediment pathways from a river to a continental margin, we need to improve our understanding of sediment resuspension, as this contributes to the transfer of sediment from the prodelta to the shelf. 
While several recent observations focused on sediment resuspension events over the GoL shelf (e.g. Ferre et al., 2005; Guillén et al., 2006; Palanques et al., 2006; Bourrin et al., 2008a; Bourrin et al., 2008b; Palanques et al., 2011), only a few focused on the Rhone prodelta area (Schaaff et al., 2002; Schaaff, 2003; Lansard, 2005; Lansard et al., 2007; Marion et al., 2010). Moreover, because of the spatial limitation of these observations, resuspension processes on the whole Rhone prodelta remain poorly understood. Numerical models can be used to fill the gap between our understanding of sediment-transport processes provided by local observations, and sedimentation patterns over the prodelta. Sediment transport models have already been successfully used over the GoL (Ulses, 2006; Ferre et al., 2008; Ulses et al., 2008) and have helped to understand off-shelf sediment export through canyons. It is now a key issue to focus on resuspension processes using innovative modelling techniques over the Rhone prodelta, and in particular to develop a high-resolution model specially refined on this area.

In the present study, field measurements performed over a three-month period were combined with a high resolution three-dimensional sediment transport model to understand the relationship between winter storms, sediment resuspension over the Rhone River prodelta and fate of sediment within the GoL. The hydro-sedimentary experiment, called SCOPE, that took place during the winter $2007 / 2008$ was first used to quantify resuspension processes and validate our model. The model was then used for further investigations focusing on the effect of extreme events on the sediment dynamics of the Rhone prodelta and of the GoL. The paper is structured as follows: after a brief presentation of the study area, we describe the SCOPE field experiment and the sediment transport model developed for the prodelta/GoL case study. In section 4, we jointly analyse experimental and modelling results and validate the model. This is followed by a discussion on the various results and conclusions. 


\section{Regional setting}

The Gulf of Lions, located in the north-western Mediterranean Sea (Figure 1), is hydrodynamically complex as several intense and strongly varying processes coexist. Millot (1990) described the main hydrodynamic patterns: a) the general south-westward circulation along the slope, called the Northern Current; b) wind-induced currents; and c) the formation of dense water both on the shelf and offshore. Over the shelf region the wind-driven circulation prevails. Intense and frequent continental winds (the Mistral in the eastern part of the GoL and the Tramontane in the western part) drive the surface waters offshore and induce local upwelling (Estournel et al., 2003). On-shore winds (mainly winds from the east and the south-east) are less frequent and result in the accumulation of water on the coast and the downwelling of surface water (Estournel et al., 2003). The cold dry continental winds which appear during winter also generate dense water on the shelf. This dense water is preferentially formed on the western part of the shelf and sinks on the south-western end part of the shelf causing dense water to cascade through the canyon (Dufau-Julliand et al., 2004).

Both on-shore and off-shore winds also generate waves within the GoL. Due to small fetch, continental winds produce small waves (significant height $<2 \mathrm{~m}$ and peak period $<6 \mathrm{~s}$ ), whereas the north-westward swell induced by less frequent onshore winds, can reach $10 \mathrm{~m}$ with a peak period of $12 \mathrm{~s}$ (The Medatlas Group: Gaillard et al., 2004; Ulses et al., 2008).

The Rhone River, which divides into two branches (the Grand Rhone and the Petit Rhone) about $50 \mathrm{~km}$ upstream the main river mouth near Arles, is a significant source of sediment for the whole GoL. It is responsible for about $94 \%$ of total solid fluxes into the GoL with a mean discharge of $10 \mathrm{Mt} / \mathrm{year}$ (Bourrin and Durrieu de Madron, 2006). The Rhone River releases $80 \%$ of the annual amount of sediments in several days of flooding (Rolland, 2006) and the 
solid discharge is characterised by a strong seasonal and inter-annual variability (Eyrolle et al., 2012).

High-discharge events of the Rhone river are not coincident with energetic oceanic conditions (strong winds, waves or currents) in the GoL, impacting the deposition of riverine sediments (Drexler and Nittrouer, 2008). Indeed, most of the sediments discharged by the Rhone River are initially deposited close to the river mouth (Noël, 1996; Lansard, 2005; Maillet et al., 2006). Sediments from the Rhone River can also be exported directly to the GoL through the river plume (Naudin and Cauwet, 1997), whose orientation is controlled by the wind. The river plume is directed south-westward and extends far offshore during continental winds, while it moves toward the west of the river mouth, following the coastline, during on-shore wind events (Pauc, 1970; Arnoux-Chiavassa et al., 1999).

Maillet et al. (2006) estimated that $90 \%$ of the sediment discharged during a major flood (December 2001) have been deposited on the Rhone prodelta between 0 and $20 \mathrm{~m}$ depth. The Rhone prodelta, which covers about $30 \mathrm{~km}^{2}$ downstream the Grand Rhone river mouth, is characterised by fine-grained sediment downstream from the $20 \mathrm{~m}$ isobath (Maillet, 2005; Roussiez et al., 2005). In this area, net sedimentation rates are estimated to range from 30 to $50 \mathrm{~cm} \mathrm{y}^{-1}$ (Calmet and Fernandez, 1990; Charmasson et al., 1998; Radakovitch et al., 1999; Miralles et al., 2005) and deposition can reach $1 \mathrm{~m}$ in some places during exceptional floods (Maillet et al., 2006). The Rhone prodelta acts as a temporary sink for riverine sediment, which can be subsequently eroded and transported south-westward during winter storm from the south-east (e.g. Lansard, 2005; Roussiez et al., 2006; Drexler and Nittrouer, 2008; Ulses et al., 2008; Marion et al., 2010). The sediment erosion process in the Rhone prodelta has been tackled mainly through the estimation of both the erosion rate and sediment shear strength in the vicinity of the Rhone River mouth (Schaaff et al., 2002; Schaaff, 2003; Lansard, 2005; Lansard et al., 2006). At the scale of the whole shelf, studies on sediment 
resuspension highlighted the role of winds from the south-east and dense water formation on the off-shelf sediment export at the south-western end of the shelf (Ferre et al., 2005; Guillén et al., 2006; Bourrin et al., 2008a; Ulses et al., 2008).

The sedimentological setting of the shelf, described by Got and Aloisi (1990), partly reflects the complex sediment dynamics detailed above (Dufois et al., 2008). The GoL shelf presents various sediment facies, from a sandy inner-shelf, where wave forcing is dominating, to a low-energy middle shelf characterised by deposition of cohesive sediments (Figure 1).

\section{Materiel and methods}

\subsection{The SCOPE experiment}

The SCOPE experiment focused on the sediment resuspension in the prodelta. To study the main forcing of the sediment dynamics and its response, three in situ devices were deployed for a period of three months (from October $28^{\text {th }}, 2007$ to January $29^{\text {th }} 2008$ ) near the cardinal mark La Balancelle (4320'31.98 N, 455'18.72 E, see Figure 1) whose bathymetry reaches $21 \mathrm{~m}$. An upward-looking Acoustic Doppler Current Profiler (ADCP) operating at $1200 \mathrm{kHz}$ was deployed on a trawl-resistant bottom platform. Current and backscattering profiles were measured every 10 minutes from $2 \mathrm{~m}$ above the bottom to the surface with $1 \mathrm{~m}$ cells. The ADCP was equipped with a wave processing module to compute sea state measurements every hour. Turbidity was also measured at $2 \mathrm{~m}$ above the bottom with a turbidimeter equipped with a WETLABS sensor. An ALTUS altimeter (autonomous $2 \mathrm{MHz}$ acoustic transducer) was also moored above the bottom to record bed sediment variations (Jestin et al., 1998; Bassoullet et al., 2000). 


\subsubsection{ADCP calibration}

Using ADCP backscattering to compute suspended sediment concentration required it to be calibrated from the turbidity data following the method proposed by Tessier et al. (2008). Before empirical calibration, the ADCP backscattered intensity was corrected for acoustic transmission losses, including spherical spreading and water absorption. Due to the range of suspended sediment concentrations generally encountered in the area (i.e. below $200 \mathrm{mg} / 1$ (Naudin and Cauwet, 1997)), the attenuation from suspended sediment was not accounted for (Tessier, 2006). The method of ADCP calibration is explained in more details in appendix A.

\subsection{Numerical model}

The numerical modelling platform combined a chain of different models. Firstly, three oneway nested wave models were run offline to compute wave parameters. Then a two level chain of two-way nested circulation models was run together with the online coupled sediment transport module using wave model results. The models are described below.

\subsubsection{Sea state modelling}

Wave fields were simulated with three nested third generation wind-wave models. A WAVEWATCH-III (Tolman, 2002a,b) model, modified by Ardhuin et al (2007), was implemented at the regional scale (western Mediterranean Sea, $0.1^{\circ}$ resolution) (Dufois et al., 2008) and provided southern boundary conditions for a higher resolution (1.2 km) SWAN model (Booij et al., 1999; Ris et al., 1999) which was centred in the northern GoL (dotted 
grey box on Figure 1). Embedded in this model was a high resolution (240 m) SWAN model focused on the Rhone prodelta (black box on Figure 1).

These models are based on the two-dimensional wave action balance equation including energy density generation and dissipation terms by wind, white-capping, wave-bottom interaction, and redistribution of wave energy due to wave-wave interactions. For the present application, both SWAN and WW3 models were forced by Météo-France wind analysis with a horizontal resolution of $0.1^{\circ}$. The regional model WW3 was first validated and compared with other models for two periods in 2002 and 2003 (Ardhuin et al., 2007) and then for the year 2001 (Dufois, 2008; Dufois et al., 2008).

\subsubsection{Coastal circulation model}

Circulation modelling was performed using the operational MARS-3D code (3D hydrodynamical Model for Applications at Regional Scale), a three-dimensional model with reduced $(\sigma)$ vertical coordinates based on the resolution of the primitive equations (Lazure and Dumas, 2007, http://www.previmer.org). This free surface model is based on the model of Blumberg and Mellor (1987) as primitive equations are solved using a time-splitting scheme under assumptions of Boussinesq approximation, hydrostatic equilibrium and incompressibility. The mode splitting technique is built with an iterative and semi-implicit method, and allows simultaneous calculation of internal and external modes within the same time step. The external mode is solved with an ADI (Alternating Direction Implicit) scheme (Leendertse, 1970).

The vertical turbulent diffusion of momentum, heat, salt and other tracers is computed using the formulation of Gaspar (1990). For horizontal turbulent diffusion, MARS-3D uses the Smagorinsky formulation (1963). 
Advection of momentum, salt, heat and other tracers is low-diffusive, as the model uses a Quick scheme (Leonard, 1979) which switches to a first order upwind scheme in case of strong gradients (in order to avoid severe overshoots).

For our application, two domains were nested using the AGRIF Fortran package (Adaptative Grid Refinement in Fortran, Debreu et al., 2008). The AGRIF version used two-way nesting for all tracers, i.e. salt, temperature and suspended sediments, whereas velocity and elevations are coupled using a one-way technique (for mass conservation consideration). With the twoway nesting technique, the coarse-resolution domain provides boundary conditions for the fine-resolution domain, and the solution of the fine-resolution domain feeds back to the coarse-resolution domain. This online nesting also allows the two domains to run simultaneously and to exchange boundary conditions at each time step, and therefore provides continuous solution at the overlapping limits.

The two domains (the coarsest called GOL and the finest PRODELTA) have a spatial resolution of $1.2 \mathrm{~km}$ and $240 \mathrm{~m}$ respectively (Figure 1). The fine resolution model covers the Rhone prodelta and accounts for the hydrology of the Grand Rhone up to the town of Arles, where liquid discharge is measured. The Grand Rhone is schematised from about $50 \mathrm{~km}$ upstream from the mouth (up to Arles) by a straight channel with realistic sections (Figure 1). The vertical discretisation of both domains consists of 30 vertical $\sigma$-layers, with refined resolution near the surface and near the bottom (the surface and the bottom layer account respectively for $0.12 \%$ and $4.4 \%$ of the water height). The model is forced by atmospheric conditions (re-analysed wind field and solar fluxes provided by Météo-France ALADIN and ARPEGE models), and the daily discharge of the Rhone River (whose total discharge is split between the Grand Rhone (90\%) and the Petit Rhone (10\%)). Lateral incoming fluxes (salt, momentum and temperature) and elevations at the open boundaries of the larger GOL domain are provided by a coarser resolution model (NORMED) which simulates the northern $-10-$ 
Mediterranean basin (its southern open boundary is located at $39.5^{\circ} \mathrm{N}$ ) and was validated with temperatures from AVHRR imagery and in situ data (André et al., 2005; André et al., 2009).

\subsubsection{Modelling the impact of waves on circulation}

Additional wave forcing was used to account for the impact of waves on circulation. The concept of radiation stress, first introduced by Longuet-Higgins and Stewart $(1960,1962)$, enables near-shore circulation to be predicted with wave-averaged models. In our model, wave forcing is assumed to be barotropic and is based on the radiation stress concept following the formulation of Phillips (1977) that accounts for total transport (contribution of both waves and currents). The barotropic equations of Phillips (1977) were adapted to the advective form used in the momentum conservation equations of MARS-3D:

$$
\frac{\partial U_{i}}{\partial t}+U_{j} \frac{\partial U_{i}}{\partial x_{j}}+g \frac{\partial \bar{\zeta}}{\partial x_{i}}=-\frac{1}{\rho \bar{h}} \frac{\partial S_{i j}}{\partial x_{j}}
$$

where $U_{i}=(U, V)$ corresponds to the horizontal depth averaged velocity vector, $\bar{h}$ is the time averaged water depth, $\bar{\zeta}$ is the time averaged water elevation and $\rho$ is water density. The velocity is the sum of the mean current velocity and the Stokes drift distributed along the vertical. $S_{i j}$ are the radiation stresses as defined by Longuet-Higgins and Stewart (1960, 1962):

$$
S_{i j}=\overline{\int_{-h}^{\zeta}\left(P \delta_{i j}+\rho \tilde{u}_{i} \tilde{u}_{j}\right) d z}-\frac{1}{2} \rho g \bar{h}^{2} \delta_{i j}
$$


where $P$ is the pressure and $\tilde{u}_{i}=(\tilde{u}, \tilde{v})$ are the wave components of the horizontal velocity vector.

The wave forcing term on the right side of equation (1) is added to the MARS-3D barotropic momentum conservation equations described in Lazure and Dumas (2007). The radiation stresses are provided by the SWAN model and result from integration of the radiation stresses calculated for every component of the frequency-direction wave spectrum. For each wave component, the radiation stresses are computed following the linear theory and assuming a monochromatic wave.

To guarantee convergence between internal and external modes, the wave forcing is also added to the baroclinic equations as a homogeneous forcing along the vertical. In our model, the wave forcing is thus homogeneous with the atmospheric pressure gradient.

\subsubsection{Sediment transport strategy}

The grain-size distribution on both the Rhone prodelta and the GoL shelf (Got and Aloisi, 1990; Dufois et al., 2008) reveals high sediment spatial variability. Considering that sediment exhibits non-cohesive behaviour when the sand fraction exceeds 70\% (Mitchener and Torfs, 1996; Panagiotopoulos et al., 1997; van der Wal et al., 2005; Le Hir et al., 2008), the inner shelf $(<30 \mathrm{~m})$ generally appears to be covered by non-cohesive sediment, whereas the rest of the shelf appears to behave as a cohesive structure. Our modelling strategy had to account for both cohesive and non-cohesive behaviours. The module used for this study is based on the fine sediment transport model SiAM (Cugier and Le Hir, 2000; Le Hir et al., 2001; Cugier and Le Hir, 2002), and several modifications were made to account for the specificity of our 
study area. These modifications partly followed previous developments made by Waeles (2008) and Waeles et al. (2005) to model the transport of sand or of sand/mud mixtures.

\subsubsection{Transport of mud/sand mixtures}

While fine sediments are transported as suspended load advected by the main flow, sands, with much higher settling velocities, can also be transported along the bed in the form of sliding and rolling grains (Soulsby, 1997). Therefore, modelling strategies usually differ for computing the horizontal fluxes for sand or mud. Sand transport rates are classically determined at the equilibrium using so-called parametric models, empirically deduced from experimental data (e.g. Meyer-Peter, 1948; Einstein, 1950; van Rijn, 1984; Camenen and Larroudé, 2003). Fine sediment transport is generally modelled using an advection-diffusion equation, and the transport rate results from the vertical integration of the product of fluid velocity and the concentration of suspended sediments (e.g. Whitehouse et al., 2000).

When modelling the transport of mixtures of sand and mud, it is useful to use the same strategy to compute horizontal fluxes of sand and mud. In recent modelling studies dealing with mixed sediment, it has become usual to transport both sand and mud using an advectiondiffusion equation (Chesher and Ockenden, 1997; van Ledden and Wang, 2001; Sherwood et al., 2004; Ulses et al., 2008; Waeles et al., 2008).

Our model follows this strategy and each sediment fraction is thus transported in the water column resolving the following equation:

$$
\frac{\partial C}{\partial t}+\frac{\partial u C}{\partial x}+\frac{\partial v C}{\partial y}+\frac{\partial\left(w-W_{s}\right) C}{\partial z}=\frac{\partial\left(K_{h} \frac{\partial C}{\partial x}\right)}{\partial x}+\frac{\partial\left(K_{h} \frac{\partial C}{\partial y}\right)}{\partial y}+\frac{\partial\left(K_{z} \frac{\partial C}{\partial z}\right)}{\partial z}+E-F_{d}
$$


where $C$ is the suspended sand or mud concentration, $K_{z}$ and $K_{h}$ are respectively the vertical and the horizontal turbulent diffusion, $(u, v, w)$ are the three velocity components, $W_{s}$ is the settling velocity and $E$ and $F_{d}$ are the source and sink terms (erosion and deposition), respectively.

In this equation, deposition flux $F_{d}$ and settling velocity $W_{s}$ are dependent on the sediment class concerned, whereas erosion $E$ is dependent on the seabed sediment state (cohesive or non-cohesive). For a mud mass fraction $p_{m}$ of less than $30 \%$, sediment is assumed to be purely non-cohesive, and purely cohesive when the mud fraction exceeds $50 \%$ (Waeles et al., 2008). Moreover, given that flocculation processes occur in our study environment (Thill, 1999; Thill et al., 2001; Durrieu de Madron et al., 2005; Bourrin et al., 2008b), we assume that mud particles are not present as primary particles in the water column. Only one class of mud, comprising either flocs or aggregates, is thus incorporated in the model, together with two classes of sand (fine and medium).

The modelling strategy for the three sediment classes is summarized below:

(i) Sand and mud are transported in suspension only. No bedload is considered for sand.

(ii) Mud flocculation is accounted for.

(iii) Sediment erodibility depends on the sediment state (cohesive or non-cohesive) within the seabed. No sediment consolidation is accounted for.

In agreement with this modelling strategy the terms $E, F_{d}$ and $W_{s}$ for the three sediment classes are detailed below. 


\subsection{Settling velocity}

- The settling velocity $W_{s}$ of the two sand classes is defined following Soulsby (1997). The fine sands with a diameter of $160 \mu \mathrm{m}$ have a constant settling velocity of $2 \mathrm{~cm} / \mathrm{s}$ and the coarse sands with a diameter of $380 \mu \mathrm{m}$ have a settling velocity of $5 \mathrm{~cm} / \mathrm{s}$.

- The mud class is characterised by a varying settling velocity. Aggregation processes, which modify aggregate size and density (and therefore their settling velocity), are schematically taken into account through the formulation of the settling velocity, which depends on both sediment concentration and turbulence. The settling velocity formulation also accounts for hindered processes, which decrease the settling velocity at high concentration levels.

We compute the settling velocity (in $\mathrm{mm} / \mathrm{s}$ here) for mud as follows:

$W_{s}=\min \left(\gamma k_{1} C^{n}, W_{s 0}\left(1-k_{2} C\right)^{\beta}\right)$

Equation (4) corresponds to Thorn's equation (1981) when $\gamma=1$. In our application $W_{s 0}=2.6$ $\mathrm{mm} / \mathrm{s}, k_{2}=0.008$ and $\beta=4.65$ correspond to the values proposed by Thorn (1981). The parameter $\gamma$ has been integrated to Thorn's equation (1981) to account for the impact of turbulence on the aggregation processes. We compute $\gamma$ in equation (4) using the expression of settling velocity proposed by van Leussen (1994) (i.e. $W_{s}=\gamma k_{l} C^{n}$ ) in which:

$\gamma=\frac{1+a G}{1+b G^{2}}$ 
The $a$ and $b$ parameters are chosen to be constant and equal to the values proposed by van Leussen (1994), i.e. $a=0.3$ and $b=0.09$. The dissipation parameter $G$, which describes the turbulent state of the system, is determined from the vertical turbulent diffusion model of Gaspar (which computes the turbulent dissipation rate $\varepsilon$ ) using $G=\sqrt{\frac{\varepsilon}{v}}$ (where $v$ is the kinetic viscosity).

A minimum settling velocity of $10^{-2} \mathrm{~mm} / \mathrm{s}$ is also imposed to equation (4). The $k_{1}$ and $n$ parameters in equation (4) are highly dependent on the study site (van Leussen, 1994; Winterwerp, 1999). In this study, the two parameters $k_{l}$ and $n$ were respectively set to 1.5 and 1 after running sensitivity tests (cf. section 4.1.2). The settling velocity of the mud class finally ranges from $10^{-2} \mathrm{~mm} / \mathrm{s}$ for low concentration (i.e. below about $6 \times 10^{-3} \mathrm{~g} / \mathrm{l}$ ) to 3.15 $\mathrm{mm} / \mathrm{s}$ at the maximum when concentration and turbulence are optimums (i.e. $G$ around $1.4 \mathrm{~s}^{-1}$ and $C$ around $1.7 \mathrm{~g} / \mathrm{l})$.

\subsection{Deposition}

\section{Mud deposition}

Mud concentration vertical gradients are smooth due to low settling velocity, thus the deposition term of mud fraction is computed directly from the concentration $C$ calculated in the middle of the bottom layer as follows:

$$
F_{d}=W_{s} C
$$

\section{Deposition and transport of sands}

Unlike the mud concentration, which can be considered to be fairly homogeneous in each vertical $\sigma$-level of the model, the sand concentration is highly heterogeneous along the vertical. Moreover, sand transport mainly takes place near the bed where velocity increases 
rapidly with height above the bed. It is therefore necessary to apply a correction procedure for the near-bed concentration, and also for the near-bed horizontal flux. To this end, the model is modified and calibrated following Dufois (2008). In that study, the capacity of the model to reproduce experimental sand transport fluxes by advection/diffusion was evidenced for a range of fine sands. The corrections applied to the model are summarized below.

For the sand fractions, a near bottom concentration $C_{b o t}$ is used to compute the deposition flux using equation (6). Thus the modelled concentration (in the middle of the bottom layer) is extrapolated at $z=2.5 D$ (where $D$ is the sand diameter) from the bottom assuming that the concentration profile follows a Rouse profile.

Within the bottom layer, where most of the sand transport occurs, the transport rate calculated by the model (from the product of the velocity and the concentration in the bottom layer) is corrected to compensate for the low vertical resolution. This correction is made considering that (i) the concentration follows the previous extrapolated Rouse concentration profile, and assuming that (ii) the velocity follows a logarithmic profile. The corrected transport flux in the bottom layer is then deduced from the vertical integration of the product of the assumed velocity profile and the assumed concentration of suspended sediments.

\subsection{Erosion}

The erosion flux formulation is expressed for each sediment class depending on its proportion $p_{i}$ as:

$$
E_{i}=p_{i} E_{0, i}\left(\frac{\tau_{s f}}{\tau_{c, i}}-1\right)^{\alpha_{i}} \text { if } \tau_{s f}>\tau_{c, i} \text { and otherwise } E_{i}=0
$$


The $i$ index corresponds to the sediment class and equals $s 1$ for the fine sands, $s 2$ for the medium sands and $m$ for the mud class. $\tau_{s f}$ is the skin shear stress computed as described in appendix B. We assume that when the sediment is cohesive all fractions are eroded together (i.e. block erosion), but that each fraction of non-cohesive sediments is eroded separately (i.e. differential erosion). The erosion rate parameter $E_{0, i}$, the critical shear stress $\tau_{c, i}$ and the constant $\alpha_{i}$ are therefore dependent on both the sediment class and the sediment behaviour within the seabed (cohesive or non-cohesive). Those parameters are chosen according to in situ experiments or model calibration/validation as detailed below.

\section{- Cohesive sediment $(p m>50 \%)$ :}

For cohesive sediments, the erosion flux is parameterised following the formulation determined from erodibility measurement of surficial mud-sand sediment near the Rhone River mouth (Dufois, 2008). All sediment classes ( $m, s 1$ and $s 2$ ) are assumed to be eroded together following equation (7) with the same erosion rate parameter $E_{0, i}=0.68 \times 10^{-3} \mathrm{~kg} / \mathrm{m}^{2} / \mathrm{s}$, the same critical shear stress $\tau_{c, i}=0.35 \mathrm{~N} / \mathrm{m}^{2}$ and the same $\alpha_{i}=1.65$.

The critical shear stress is set at $0.35 \mathrm{~N} / \mathrm{m}^{2}$, regardless of the sediment compaction and composition. This formulation was shown to successfully predict the measured fluxes of surficial sediment in the prodelta area (Dufois, 2008).

\section{- Non-cohesive sediment $\left(p_{m}<30 \%\right)$ :}

The erosion flux of each sand class within non-cohesive sediment is determined following the formulation determined by Dufois (2008). That erosion law, used in the advection/diffusion model, was shown to reproduce both experimental and theoretical transport rates for a range of fine to medium sands. Equation (7) is used for the two sand classes $s 1$ and $s 2$ with $\alpha_{s I}=\alpha_{s 2}=0.5$ and the erosion rate parameter $E_{0, s 1}=0.4 \mathrm{~kg} / \mathrm{m}^{2} / \mathrm{s}$ and $E_{0, s 2}=12.8 \mathrm{~kg} / \mathrm{m}^{2} / \mathrm{s}$. The 
critical shear stresses $\tau_{c, s l}$ and $\tau_{c, s 2}$ are determined following Wu et al. (2000) to account for hiding/exposure effects. The critical shear stress of each sand class is therefore dependant on its diameter and the presence of the other sand class.

Within these non-cohesive sediments, we assume that mud exhibits the same behaviour as within cohesive sediment and only the critical shear stress is modified, considering that mud is eroded simultaneously with the finest sand (i.e. equation (7) is used with $E_{0, m}=0.68 \times 10^{-3}$ $\mathrm{kg} / \mathrm{m}^{2} / \mathrm{s}, \tau_{c, m}=\tau_{c, s l}$ and $\left.\alpha_{m}=1.65\right)$.

\section{- Erosion of mud/sand, between cohesive and non-cohesive state:}

When the mud fraction $p_{m}$ represents between $30 \%$ and $50 \%$ of the sediment, sediment behaviour on the seabed is not clearly defined. We assume that an intermediate regime makes the transition between the two main regimes. Therefore, each sediment class is eroded separately; the parameters $\mathrm{E}_{0, \mathrm{i}}, \alpha_{\mathrm{i}}$ and $\tau_{\mathrm{c}, \mathrm{i}}$ of the erosion formulation (7) are different for each class and defined by linear interpolation between the two critical mud fractions $p_{m}=30 \%$ and $p_{m}=50 \%$. The continuity of the erosion flux between the two regimes is thus guaranteed.

\subsubsection{Sediment layers model}

A morphodynamic module is implemented to account for the variation in bathymetry over the Rhone prodelta (Maillet et al., 2006). The bathymetry of the circulation model is updated at each time step according to the net erosion/deposition flux.

In nature, any modification in the composition of the bed could lead to the creation of a surficial layer of coarse sediment, which protects the underlying finer sediment layer against erosion. This effect (called paving or armouring) is usually implemented in numerical model by using the "active layer" concept proposed by Parker (1990). In this study we did not 
include the paving effect per se. However, the sediment compartment is discretised in thin layers to account for variations in the composition of the vertical bed, and only the surface layer can be eroded. Underlying sediment is thus protected from being eroded. The initial vertical resolution in the sediment is $1 \mathrm{~cm}$ and we numerically maintain a vertical resolution ranging from 0.5 to $1.5 \mathrm{~cm}$ in the sediment. The surficial layer is either divided into two after deposition if it exceeds $1 \mathrm{~cm}$, or merged with the underlying layer after erosion if it drops below $0.5 \mathrm{~cm}$.

Moreover, due to lack of knowledge concerning the erosion processes of consolidated sediment in the area, the process of consolidation is not accounted for in the model.

\subsubsection{Initialisation and boundary conditions}

The three particle size classes were initialised from the updated sediment cover using results of recent laser grain-size analyses (Dufois et al., 2008). The map of the sand fraction, including both fine and medium sand fractions illustrates this initialisation (Figure 1).

Suspended sediment concentrations were imposed at the upstream boundary of the flume representing the Rhone River (at Arles). Sediment discharge was deduced from water discharge using the formulation of Thomas (1997). According to grain size measurements for different river discharge conditions in the Rhone River (Antonelli et al., 2007), we considered that on average $90 \%$ of the suspended concentration is supplied by mud, and that the two sand classes are equally discharged. The same suspended sediment concentrations were imposed directly at the river mouth of the Petit Rhone, which lies outside the PRODELTA domain. 
Moreover, discharged riverine mud is tracked in order to differentiate it from mud originally present in the seabed. This does not affect the behaviour of the fine sediments in the model as those two kinds of mud belong to the same particle size class.

\section{4. $\underline{\text { Results }}$}

In this section, we compare observations and model results in order to i) evaluate the model at a fixed station, and ii) extrapolate the results at a larger scale. In the figures presented in the following sections, model outputs are mostly in grey or blue and in situ measurements in black or red.

\subsection{La Balancelle station}

\subsubsection{Hydrodynamic conditions}

The forcing variables of the sediment dynamics (measured river discharge, re-analysed wind, measured and modelled wave and current) at La Balancelle station are summarized in Figure 2. The SCOPE experiment was characterised by frequent Mistral events ( $\mathrm{N}$ to NW winds) and a few wind events from the south-east. The wind events from the south-east reaching up to $20 \mathrm{~m} / \mathrm{s}$ were linked with the most energetic wave events (significant wave height $\left(\mathrm{h}_{\mathrm{s}}\right)$ above $3 \mathrm{~m}$ and mean periods $\left(\mathrm{T}_{\mathrm{m}}\right)$ around $6 \mathrm{~s}$ ). The wave parameters were well simulated at this near-shore location (Figure 2 and Table 1) with a relative error (Scatter Index (SI), cf. appendix C) of about $20 \%$ for both $\mathrm{T}_{\mathrm{m}}$ and $\mathrm{h}_{\mathrm{s}}$, which confirmed the efficiency of the wave modelling strategy. ADCP profiles displayed two main patterns: i) the current directions were relatively homogeneous over the water column, except at (approximately) four metres near 
the surface (data not shown); ii) the main currents were parallel to the NE-SW orientation of the isobaths at this position. The currents were never oriented towards the coast (NW) unless they were very low (inducing high uncertainty concerning the direction of the current). The best correlation (0.54) between wind velocity and observed current velocity was found when the wind is leading the current by 7 hours. Furthermore, during significant wind events from the south-east, currents were generally south-westward and appeared to be favourable to an alongshore export of sediment.

Although the model reproduces the main hydrodynamic characteristics at a regional scale (André et al., 2005; André et al., 2009), the comparison between ADCP currents and modelled currents at La Balancelle highlighted the difficulty to simulate currents at a fixed point (Figure 2e-g). A weak relationship between modelled and measured velocity amplitude was found when considering the whole experimental period, with for example a correlation of 0.47 for the depth averaged (from 2 to 16 metres above the bottom (mab)) velocity (U) (Table 1). The comparison of the depth averaged velocity direction (Dir) (Figure $2 \mathrm{f}$ ) leads to a better correlation (0.73), whereas the root mean square error (RMSE, appendix C) is high $\left(88^{\circ}\right)$. [N.B.: to compare the ADCP directions $\theta_{A D C P}$ and the modelled directions $\theta_{m}$ (in Figure $2 \mathrm{f}$ and Table 1) we require $-180^{\circ} \leq \theta_{A D C P^{-}}-\theta_{m} \leq 180^{\circ}$. Therefore, when $\left|\theta_{A D C P^{-}} \theta_{m}\right|>180^{\circ}$ we adjust $\theta_{m}$ to $\theta_{m}-360^{\circ}$ or $\theta_{m}+360^{\circ}$ depending on the sign of $\left(\theta_{A D C P}-\theta_{m}\right)$. For example, if $\theta_{A D C P}=0^{\circ}$ and $\theta_{m}=359^{\circ}$ we adjust $\theta_{m}$ to $-1^{\circ}$ in order to highlight the good match between the two values].

However, from a sedimentary point of view, only energetic periods are significant. The evaluation of the circulation model should therefore be based on dynamically decisive periods. During the two strong wind events from the south-east, the match between model and data for both current velocities and directions is improved (Figure 2e-g). Indeed, the correlation between the measured and simulated magnitude of the depth averaged velocity increased to 0.64 when only energetic events were considered $\left(h_{\mathrm{s}}>2 \mathrm{~m}\right)$ (Table 1$)$. The 
statistical parameters of the model for both waves and currents were better during these periods (Table 1), with for example a relative error (SI, appendix C) of about 35\% for current amplitudes and of $12 \%$ for wave height.

Hereafter we focus on the two most energetic periods, around the $21^{\text {st }}$ November 2007 and around the $4^{\text {th }}$ January 2008 , which are expected to have the strongest impact on sediment dynamics. These two periods were similar in terms of hydrodynamics. For each event, the winds from the south-east that blew for one to two days, and reached $20 \mathrm{~m} / \mathrm{s}$ at La Balancelle, induced north-westward waves at the regional scale (in the model), which reached about 3.5 $\mathrm{m}$ at the mooring station. South-westward currents were also induced and reached 25 to 30 $\mathrm{cm} / \mathrm{s}$ at the same location.

\subsubsection{Sediment dynamics}

During the experimental period, measured river discharge ranged from 300 to $3200 \mathrm{~m}^{3} / \mathrm{s}$ (Figure 2a). According to Pont et al. (2002), the sediment concentration should have ranged from 10 to $200 \mathrm{mg} / \mathrm{L}$ at Arles, $50 \mathrm{~km}$ upstream of the Rhone River mouth. However, the Rhone River discharge was not found to have any impact on either the observed bed variation or on the concentration of suspended particulate matter (SPM) in the water column estimated by the ADCP (Figure 2 and 3). The moored station thus appeared to be beyond the direct influence of the Rhone River during the experimental period. Under the forcing conditions encountered during the experiment, the simulated Rhone River plume was mostly deflected toward the west, leaving the station unaffected.

The turbidity estimated by the ADCP revealed several turbid periods. Among them, those corresponding to observed wave events reaching about $2 \mathrm{~m}$ did not match any significant observed bed variations, while the SPM concentration could reach up to $120 \mathrm{mg} / \mathrm{l}$ at the 
bottom (Figure 3). These events probably induced resuspension in the shallows closer to the coast. The only periods during which strong erosions and resuspensions were observed at the mooring station coincided with the two strong storm events which resulted in the highest simulated bottom shear stress over the whole period (Figure 3). These two energetic periods, which were similar in terms of hydrodynamic forcing and induced bottom shear stresses up to about $1.7-1.8 \mathrm{~N} / \mathrm{m}^{2}$, were also similar in terms of sediment response. About 1.5 to $2 \mathrm{~cm}$ of sediment erosion was observed during each event and an increase in SPM concentrations in the whole water column ranging from 40 to $150 \mathrm{mg} / \mathrm{l}$ was observed at the mooring station (Figure 3).

At the mooring station, model outputs were compared with sedimentary data. Simulated timedepth variations in the SPM concentration were in good agreement with ADCP measurements (Figure $3 \mathrm{~b}$ and $3 \mathrm{c}$ ). The main events were reproduced at the right time at the right order of magnitude, and were simulated in the whole water column in agreement with the measurements. The modelled SPM concentration was however lower by about 20 to 30 $\mathrm{mg} / \mathrm{l}$ at the top of the water column during the second energetic event (Figure $3 \mathrm{~b}$ and $3 \mathrm{c}$ ). At the bottom (first ADCP cell) the model fitted the SPM concentration data well with a good correlation coefficient (0.76) and with a relative error (SI, appendix C) of 67\% (Figure 3c and Table 1). This relative error decreased to $63 \%$ when only energetic events were considered (Table 1). The bed variation at La Balancelle was also well modelled and the order of magnitude was close to that measured. The first bed erosion event was however stronger by about $0.5 \mathrm{~cm}$, whereas the second erosion event was weaker by about $0.5 \mathrm{~cm}$ (Figure $3 \mathrm{e}$ ). Two parameters related to the settling velocity formulation needed to be calibrated (see section 3.2.3.1.1.). Sensitivity tests were run mainly based on the validation described above. The tests showed that bed variation does not depend on these two parameters. On the 
contrary, the parameters control turbidity in the water column. The two parameters $k_{1}$ and $n$ were thus respectively set at 1.5 and 1 in order to obtain a good fit with the SPM profile. These parameters, and the associated settling velocity, were within the range of values cited in the literature (e.g. $n$ ranges from 0.5 to 3.6 (van Leussen, 1994)).

Modelled and measured cumulative suspended sediment fluxes at the mooring station were also compared. The cumulative sediment flux vector $\vec{\phi}=\left(\phi_{x}, \phi_{y}\right)=\sum_{t} \overrightarrow{U(t)} \cdot C(t) \cdot \Delta t$ (where $\overrightarrow{U(t)}$ and $C(t)$ are the velocity vector and the concentration at time $t, \Delta t$ is the time step) informs both the amplitude and the direction of sediment transport during the experiment. In Figure 4, both near-bottom (a) and depth-averaged (b) cumulative suspended sediment fluxes are given for the whole period. Most of the measured sediment flux (black line) occurred during the two storms from the south-east in the whole water column. The sediment flux during the whole experiment or during the two storms was directed south-westward. The flux appeared to be homogeneous along the vertical, as the near-bottom and depth-averaged curves were almost the same (black curves in Figure 4). Moreover, the modelled suspended sediment flux appeared to satisfactorily reproduce in situ measurements. Although the nearbottom cumulative flux was higher by a factor 1.7 , the depth averaged flux fit the data well. Thus, even if the currents were not always perfectly reproduced at La Balancelle station, this analysis showed that the model was able to reproduce the main pattern of erosion and sediment flux at the mooring station. As the sediment flux was nearly zero except during storms from the south-east, from the point of view of sediment transport, the ability to correctly simulate current direction during energetic periods is the most important.

\subsection{Fate of sediment on the Rhone River prodelta and on the Gulf of Lions}




\subsubsection{Meteorological conditions}

The re-analysed winds and simulated waves at the mooring station were representative of the forcing at the regional scale. The two major wave events at the scale of the GoL coincided with the two main events at La Balancelle station. The first storm from the south-east, whose peak waves were higher than $4 \mathrm{~m}$ in the middle of the GoL during the night of November $20^{\text {th }}$, was characterised by strong winds reaching $20 \mathrm{~m} / \mathrm{s}$ (Figure $5 \mathrm{a}$ ). These strong winds impacted the whole GoL during the storm, whereas the waves were higher on the northern part of the shelf. This storm induced bottom shear stresses, mostly induced by waves, higher than $0.33 \mathrm{~N} / \mathrm{m}^{2}$ upstream of the $50 \mathrm{~m}$ isobaths, and reaching up to $4 \mathrm{~N} / \mathrm{m}^{2}$ closer to the shore (Figure $5 b$ ). The bed shear stress pattern computed during this first storm corresponds to the highest values obtained at the regional scale during the whole experiment period. The second storm from the south-east presented a similar wind field, but simulated waves were higher in the middle of the GoL where they reached $5 \mathrm{~m}$. The bed shear stress pattern computed during the second storm is very similar to the one shown on Figure $5 \mathrm{~b}$.

\subsubsection{Validation of the model at the regional scale}

At the regional scale, ocean colour satellite images were available to validate the sediment transport model during the SCOPE experiment. MODIS/AQUA images were used to estimate the SPM concentration using the OC5 empirical algorithm developed at IFREMER (Gohin et al., 2005). This algorithm was calibrated with water from both the English Channel and the Bay of Biscay continental shelf, and was validated later in the GoL (Fontana et al., 2009). 
Due to the cloud cover during storms from the south-east, images were unfortunately not available for the most interesting events. Consequently we show two images acquired two and four days after the first storm from the south-east, together with the model simulation (Figure 6). Those two MODIS images exhibit among the highest SPM concentrations of the whole set of SST satellite images available during the experiment.

During the two days concerned, with re-analysed winds from the north/north-west reaching $12 \mathrm{~m} / \mathrm{s}$, simulated waves progressively increased to $3 \mathrm{~m}$ in the GoL while propagating southward. The measured Rhone River discharge reached its maximum for the experimental period with respectively 3200 and $2700 \mathrm{~m}^{3} / \mathrm{s}$ at Arles. In Figure $6 \mathrm{a}$ and $6 \mathrm{c}$, it can be seen that a surface SPM plume was still present along the coast a few days after the storm although both wind and waves had decreased (Figure 2). It can also be seen that a wind from the northwest over the GoL led to the extension of the Rhone River plume towards the south-west. For the two days concerned, both the extent and order of magnitude of the Rhone River and of the resuspension plume were well reproduced by the model (Figure $6 \mathrm{~b}$ and $6 \mathrm{~d}$ ). The modelled resuspension plume along the GoL coastline after the storms was however slightly overestimated (by about 10 to $20 \mathrm{mg} / 1$ on average).

The capacity of the model to reproduce the surficial SPM concentration during the SCOPE experiment has also been statistically estimated using the 52 MODIS images available. However, due to cloud contamination, the statistical parameters presented on Figure 7 have not necessarily been computed with 52 values for each pixel. The pattern of mean surface SPM values computed by the model and estimated by satellite were consistent (Figure 7a and $7 \mathrm{~b}$ ), although the model was on average positively biased over the shelf region by about 2 $\mathrm{mg} / \mathrm{l}$. The model exhibited good performance indicators, although very spatially variable. The temporal variability seemed to be satisfactorily reproduced over the shelf with correlations globally higher than $50 \%$ in regions with higher SPM values, notably along the coast and 
within the Rhone River plume. The relative error (Scatter Index) seemed reasonable in most areas, notably close to the Rhone prodelta where it did not exceed $60 \%$. There were however two main areas, east of the Rhone prodelta and on the south-west corner of the GoL, where relative errors were high. Those two regions corresponded to places with bias smaller that 3 $\mathrm{mg} / \mathrm{l}$ but very low concentrations estimated by satellite, inducing a large relative error.

\subsubsection{Impact of winter storms}

Validation at various spatial and time scales gave us confidence to investigate results of the model at regional scale. At the moored ADCP position, the whole period was mainly influenced by the two storms from the south-east (Figure 3). The same conclusion was true at the scale of the PRODELTA domain. Figure 8 shows the simulated sediment budget over the PRODELTA domain throughout the experimental period. Mud and sands are distinguished here. For each vertical level in the sediment, the relative concentration of both sand and mud was known. The net sediment bed evolution was thus divided into changes in the mud budget and in the sand budget (i.e. the net sediment bed evolution is the sum of changes in both the mud and sand budgets). For both sand and mud, the model showed that the main variations in the sediment budget (including both suspended sediment and sediment bed) occurred during the main storms.

On average, the PRODELTA domain was impacted by two strong erosion events. As can be seen in Figure 8, the two storm events had the same impact at the PRODELTA scale. Therefore, the description of the spatial impact of storms from the south-east only focuses on the first storm.

During the first storm, simulated currents in the GoL were generally north-westward at the surface and turning more south-westward closer to the bottom. They evidenced the SPM 
export toward the south-western end of the shelf generated by winds from the south-east (Figure 9).

During these storms from the south-east, the resuspended SPM plume estimated from the model was flattened against the coast at the surface due to the direction of the current. The total SPM concentration of about $100 \mathrm{mg} / \mathrm{l}$ near the surface reached a few $\mathrm{g} / \mathrm{l}$ at the bottom of the shallowest area (in agreement with measurements made by Palanques et al. (2008) which reached $3 \mathrm{~g} / \mathrm{l}$ at $0.15 \mathrm{mab}$ at a depth of $28 \mathrm{~m}$ in the western part of the Gulf during strong storms). The turbid plume was more extensive at the bottom than at the surface all over the GoL. Unlike the surface current, the simulated bottom currents slightly steered away from the coast and thus led to SPM cross-shore export. At the south-western end of the shelf (near Cap de Creus), strong currents combined with increasing SPM concentrations also resulted in offshelf SPM export. Moreover, the SPM plume pattern observed and simulated several days after the storm all over the GoL (Figure 6) highlighted its long-lasting impact.

\subsubsection{Sediment budget during the experimental period}

We now present the contribution of both sand and mud to net variations in the sediment bed simulated at the end of the experiment, i.e. after the two storms (Figure 10). As can be seen in Figure 8 , simulated variations were driven by the two storms, and the sediment balance in Figure 10 was consequently about twice that induced by one storm. 
At the PRODELTA scale, significant erosion of sand and mud reaching in total up to $10 \mathrm{~cm}$ was simulated down to the $20 \mathrm{~m}$ isobath. Depositions reaching $\pm 3 \mathrm{~cm}$ were simulated around the $50 \mathrm{~m}$ isobath mainly driven by sand dynamics. There is also a sand deposition area reaching up to $10 \mathrm{~cm}$ right at the river mouth. Net sediment changes were higher in the PRODELTA area than in the GoL, where neither deposition nor erosion exceeded $3 \mathrm{~cm}$.

At the PRODELTA scale, both sands and mud were responsible for the main variations in the bed (Figure 10). However, modelled sediment exports were dominated by mud (Figure 8 ). Throughout the period, exports of mud from the PRODELTA domain were twice as high as exports of sand. Each of the two storms induced an export from the PRODELTA area of about 2.1 Mt of sediment (which corresponds to 3.5 times the Rhone River solid discharge). Some of the resuspended sand was not exported far from the coast, depositing down to the 25 $\mathrm{m}$ isobath (Figure 10). In contrast, only a few mud deposition areas were simulated on the PRODELTA domain; resuspended mud was mainly exported out of the PRODELTA domain. Mud erosion areas were simulated around the $20 \mathrm{~m}$ isobath where the wave impact was still strong and where the mud fraction increased (Figure 1).

At the GOL scale, variations in the bed were mainly simulated around the $50 \mathrm{~m}$ isobath in muddy areas (Figure 1 and Figure 10). Main mud deposition areas were also simulated directly downstream from the same isobath.

During the whole period, about 4.4 Mt of sediments were exported out of the PRODELTA domain (Table 2), whereas only 0.5 Mt were discharged by the Grand Rhone ( $0.05 \mathrm{Mt}$ by the Petit Rhone). Moreover, only 34\% of the particulate matter discharged by the Grand Rhone accumulated in the prodelta. The Rhone River prodelta was thus deficient in mud in the simulation during the SCOPE experiment as solid discharge supplied only $6 \%$ of the mass that was eroded and exported. Fine sediments were rapidly dispersed over the GoL. About half the solid discharge from the Rhone River was exported out of the GOL. This rapid -30 - 
dispersion also resulted in the export of about $6 \mathrm{Mt}$ of bed sediments. The GoL was thus deficient during the simulation period.

\section{Discussion}

Concerning the influence of wave forcing on the current, Figure 11 shows that during energetic events, wave forcing should not be disregarded. It may even be predominant close to the mouth of the Rhone River. Modelled wave-induced circulation was relatively high during the peak of each storm event. Major currents were generated by the waves upstream of the $20 \mathrm{~m}$ isobath and reached their maximum (approximately $0.8 \mathrm{~m} / \mathrm{s}$ ) near the mouth of the Rhone River close to the $5 \mathrm{~m}$ isobath. Two main current branches were simulated along the coast. The first one ran north-eastward on the east side of the river mouth while the second one ran westward on the west side of the river mouth. Although the comparison at the ADCP location at $18 \mathrm{~m}$ depth may not the most appropriate to validate the impact of the wave forcing in the model (Figure 11), the comparison between simulated and measured depthaveraged velocity proved to be better when the wave forcing was added (e.g. the relative error (SI) was about $5 \%$ lower).

Wave-induced current is likely to have an influence on sediment transport, particularly on the export of sediment from the prodelta region shallower than $20 \mathrm{~m}$. However, the horizontal resolution of the model limits the ability to accurately reproduce wave-current interactions. The resolution needs to be fine enough to allow simulation of both shoaling and wave-bottom processes when the waves reach the coast (i.e. less than $100 \mathrm{~m}$ ). Thus, with a resolution of 1.2 $\mathrm{km}$, the wave forcing in the GOL domain was not well represented and the effect on the circulation was much too small. The model exhibited marked discontinuity in sedimentation at the western boundary between the GOL and the PRODELTA (Figure 10), which was 
mainly due to wave-induced current discontinuity between the two domains. Consequently, it was the change in resolution that induced rapid deposition of the sands during the advection through the boundary. This observation underlines the need to run a high resolution hydrodynamic and sediment transport model in the area of primary interest. Hence, sediment fluxes could have been accurately estimated in the PRODELTA area, whereas sediment transport (particularly transport of sand) could have been underestimated close to the coast in the GOL area.

Sediment resuspension played a major role in the dispersion of riverine sediment in the study area during the SCOPE experiment. Resuspension from the prodelta implies an earlier phase of sediment deposition. Drexler and Nittrouer (2008) highlighted the lack of temporal coherence between Rhone River discharge and meteorological/oceanographic conditions in the GoL and its impact on the deposition of riverine sediment close to the river mouth. During the SCOPE experiment, the storms and the peaks of solid discharge are indeed not in phase (Figure 2).

However, a rapid dispersion of the Rhone River material was simulated during the experiment showing that only about $34 \%$ has been stored in the prodelta. Based on radionuclide analyses, Noël (1996) estimated the Rhone River sediment storage in an area of $30 \mathrm{~km}^{2}$ downstream the river mouth to be about $54 \%$ and Lansard (2005) estimated the Rhone River plutonium storage on an area equivalent to the PRODELTA domain $\left(\sim 500 \mathrm{~km}^{2}\right)$ to be about $85 \%$. The storage estimate made for our experiment, which was mainly influenced by resuspension events, cannot be compared with the estimation made over long time scales influenced by flood supply. Indeed, the SCOPE experiment period was not representative of the Rhone River discharge climatology. No flood was experienced during the SCOPE experiment, resulting into a discharge of only $0.5 \mathrm{Mt}$ of sediment, compared to the $10 \mathrm{Mt}$ of fine sediment supplied on average by the Rhone River each year (Bourrin and 
Durrieu de Madron, 2006). On the contrary the SCOPE experiment period was representative of the wave forcing climatology in the GoL. Offshore the Rhone prodelta $\left(43^{\circ} \mathrm{N}, 5^{\circ} \mathrm{E}\right)$, the storm-driven westward waves, with heights greater than $3 \mathrm{~m}$ occurred $2.3 \%$ of the time between 1992 and 2002 (The Medatlas Group: Gaillard et al., 2004) and during the SCOPE experiment those conditions happened $2.4 \%$ of the time. This could partially explain why the model estimated the Rhone prodelta to be highly in deficit of sediment during the three month period.

Since modelled and estimated sediment budget at the mooring station were in agreement, we believe that the larger scale sediment budgets estimated by the model are meaningful. We however acknowledge that both the model calculations and the data contain uncertainties which could lead to an overestimation of the sediment export fluxes, which indeed are very high. If the data comparison at the mooring site provides confidence in the model output, then it should be noted that ADCP backscatter calibration could have induced a bias in the SPM concentration estimation (cf. appendix A). Also, if the measurement of the seabed evolution is expected to have zero bias, then the good agreement between the depth of erosion from the model and from the data does not necessarily mean that the mass eroded is consistent. Indeed, the mass eroded is dependent on the sediment porosity, and thus on the level of compaction of the seabed. Finally, although great care has been taken to choose the various parameters of the model, these could have suffered from data uncertainties and limitations. Several assumptions have also been made while implementing the model. For example, consolidation processes have not been taken into account in the model and this could have led to an underestimation of the erosion threshold for cohesive sediment, and therefore an overestimation of erosion fluxes.

\section{6- Conclusion}


In this study, a sediment transport model was developed and implemented in the Gulf of Lions. Particular attention was paid to resuspension in the Rhone River prodelta and its impact over the whole GoL. For this purpose, a high resolution AGRIF zoom centred on the Rhone prodelta was embedded in a regional model of the GoL. The model was used to simulate the SCOPE experiment. This experiment, which took place during the winter 2007/2008, consisted of measuring hydro-sedimentary parameters with a mooring station composed of a current profiler (ADCP) and an altimeter (acoustic transducer) located near the Rhone prodelta.

The experimental period was characterised by two strong storms from the south-east and data analysis highlighted the strong impact of these storms. Indeed, the signals of current, SPM concentration and bed elevation showed the greatest variation during the storm events. The combined effect of strong south-westward currents and north-westward waves had a major impact on the seabed. Erosion of bed material (about $2 \mathrm{~cm}$ ) and an increase in suspended material (up to about 50-100 $\mathrm{mg} / \mathrm{l}$ ) in the water were observed during each storm.

This study highlighted the major influence of storms from the south-east on the whole GoL shelf and particularly on the Rhone prodelta. The high erosion capacity (due to waves) combined with strong currents (due both to winds and waves) resulted in a strong export capacity. It was also shown that the same forcing variables were responsible for the rapid dispersion of the Rhone River material. Rhone River sediment trapped over the Rhone prodelta may be subject to strong resuspension during episodic events. This experiment thus demonstrated that the Rhone River plume is not the only main export driving mechanism for Rhone River sediment.

In the future it would be interesting to simulate a longer period or periods during which the influence of the Rhone River is stronger. Such simulations could help quantify the respective 
impacts of the two Rhone River sediment export pathways (direct exportation by the plume or deposition/erosion/exportation) with different atmospheric forcing at a long time scale.

The comparisons presented in this study between model outputs, and both the mooring data and the satellite images, were used to parameterise the settling velocity of fine sediments. Other sets of data have also been used to set up the sediment transport model (Dufois, 2008). However, the vertical SPM concentration profiles used to set up the model depends on both the settling velocity and the turbulent vertical mixing. Further investigation should be carried out in order to validate the turbulent mixing model in the region. This would lead to a better parameterisation of the settling velocity.

This study also underlined the need to consider wave forcing over circulation particularly close to the Rhone River mouth. However, in the present study, wave forcing was implemented in a simplified way (i.e. two-dimensional forcing). In the future, a more realistic three-dimensional formulation of the wave forcing will be necessary for a detailed investigation of its effect on the sediment dynamics.

Acknowledgements: We acknowledge IRSN (Institut de Radioprotection et de Sûreté Nucléaire) and Provence-Alpes-Côte d'Azur Region for their financial support. We thank the anonymous reviewer and the editor for their helpful comments.

\section{Appendix A: ADCP calibration}

The mass concentration $M$ is linked to the ADCP signal in the whole water column by the following equation (Tessier, 2006; Tessier et al., 2008): 


$$
10 \log _{10}(M)=a . I V_{r}+b
$$

where $I V_{r}$ is the relative volume backscattering index and $a$ and $b$ are calibrated by linear regression using measurements of mass concentration acquired conjointly with the ADCP measurements.

In our experiment, the turbidity measured by the turbidimeter in the first cell of the ADCP was used to determine $a$ and $b$. However, the turbidimeter itself was not calibrated with the sediment of the area. Only two old calibrations implemented in the "Bay of Mont SaintMichel” (English Channel, France) are available for that particular turbidimeter. Nevertheless, the value of 7 NTU obtained in clear water provided information for our calibration. Thus, with this value, the turbidimeter calibrations become $M(\mathrm{mg} / \mathrm{l})=\alpha[M(\mathrm{NTU})-$ 7] with $\alpha=1.32$ or $\alpha=2.95$ ( $\mathrm{R}^{2}=0.99$ for both calibration with SPM concentration ranging from 0 to $2000 \mathrm{mg} / \mathrm{l})$. The slope $\alpha$ being a varying parameter, the ADCP calibration is done with the following equation:

$$
10 \log _{10}(M(N T U)-7)=a \cdot I V_{r}+b
$$

So that finally: $M(N T U)=10^{\left[a . I V_{r}+b\right] / 10}+7$ or $M(m g / l)=\alpha\left(10^{\left[a . I V_{r}+b\right] / 10}\right)$

The calibration of the ADCP using the turbidimeter is shown in Figure 12. However, the turbidimeter was rapidly fouled so that only about one month of measurements could be used. Moreover, even within this one month some turbidimeter measurements were disregarded (grey dots in Figure 12) as they did not fit well with the calibration. Finally, given the limited range of SPM concentrations, the resulting calibration was quite good $\left(\mathrm{R}^{2}=0.73\right)$ with a slope of 0.62 in agreement with the range of values (0.4 to 1.15) obtained by Gartner et al. (2004). The calibrated ADCP signal was able to reproduce (at least in the first cells) turbidity measurements (Figure 13). In Figure 13, the grey area corresponds to the time series that was 
disregarded in the calibration (grey dots in Figure 12). The period probably coincides with the beginning of fouling. At the end of the period, fouling continued but its influence was less due to the marked increase in the in situ SPM concentration. The period with the highest SPM concentration was consequently used.

To compare the model output with the ADCP measurement, we had to choose the $\alpha$ parameter. For the present study, we assumed that $\alpha=1.32$ keeping in mind that, as a result, the turbidity estimation could contain an error.

\section{Appendix B: Bottom shear stress}

In our study, the method to calculate the skin friction component of the total shear stress does not account for the influence of bedforms. Thus, skin friction $\tau_{s f}$ is computed as follows considering a grain-size roughness $k_{s}=2.5 D$ ( $D$ is the maximum sand grain-size encountered on the surficial sediment).

Firstly, the current induced shear stress is calculated by:

$$
\tau_{c}=\rho u_{*}^{2} \quad \text { avec } \quad u_{*}=\frac{\kappa u(z)}{\ln \left(z / z_{0}\right)}
$$

where $\rho$ is water density, $z$ is the height of the first layer above the bottom, $u(z)$ is the associated speed, and $\kappa$ is the Von Karman constant (0.4).

Secondly, the wave induced shear stress is computed from the wave parameters $\left(h_{s}\right.$ : the significant wave height, $T_{p}$ : the peak period) given by the wave models:

$$
\tau_{w}=0.5 \rho f_{w} U_{b}^{2}
$$


With $f_{w}=0.3$ if $A / k_{s}<1.57$ and otherwise $f_{w}=0.0025 \operatorname{lexp}\left(5.21\left(A / k_{s}\right)^{-0.19}\right)$ (Swart, 1974).

$U_{b}$ is the orbital velocity of the swell on the bottom, and $A$ is the orbital half-excursion near the bottom $\left(A=\frac{U_{b} T_{p}}{2 \pi}\right)$. The orbital velocity $U_{b}$ is computed as follows:

$$
U_{b}=\frac{\pi h_{s}}{\sqrt{2} T_{p} \sinh (2 \pi h / L)}
$$

where $L$ is the wave length.

The formulation of Soulsby (1997) is finally used to take non-linear wave-current interactions into account:

$$
\tau_{m}=\tau_{c}\left[1+1.2\left(\frac{\tau_{w}}{\tau_{w}+\tau_{c}}\right)^{3.2}\right]
$$

and

$$
\tau_{s f}=\left[\left(\tau_{m}+\tau_{w}|\cos \varphi|\right)^{2}+\left(\tau_{w} \sin \varphi\right)^{2}\right]^{0.5}
$$

where $\tau_{m}$ represents the average shear stress in the direction of the current, and $\varphi$ is the angle between the current and wave directions. $\tau_{s f}$ is thus the maximum shear stress generated during a wave period.

\section{Appendix C: Statistical parameters}

Simulations were evaluated using the Correlation Coefficient $(C O R)$, the bias $(B I A S)$, the Root Mean Square Error (RMSE) and the Relative Root Mean Square Error, also called Scatter Index $(S I)$.

If $x_{i}$ is the measured value at time step $i, y_{i}$ the simulated value at the same time step, $\bar{x}$ and $\bar{y}$ are respectively the mean values of $x_{i}$ and $y_{i}$ for the $N$ time steps, this gives: 


$$
\begin{array}{ll}
C O R=\frac{\sum_{i=1}^{N}\left(x_{i}-\bar{x}\right)\left(y_{i}-\bar{y}\right)}{\sqrt{\sum_{i=1}^{N}\left(x_{i}-\bar{x}\right)^{2} \sum_{i=1}^{N}\left(y_{i}-\bar{y}\right)^{2}}} & S I=\sqrt{\frac{\sum_{i=1}^{N}\left(x_{i}-y_{i}\right)^{2}}{\sum_{i=1}^{N} x_{i}^{2}}} \\
R M S E & =\sqrt{\frac{\sum_{i=1}^{N}\left(x_{i}-y_{i}\right)^{2}}{N}} \\
\text { BIAS }=\bar{y}-\bar{x}
\end{array}
$$

\section{$\underline{\text { References }}$}

André, G., Garreau, P., Fraunie, P., 2009. Mesoscale slope current variability in the Gulf of Lions. Interpretation of in-situ measurements using a three-dimensional model. Continental Shelf Research 29 (2), 407-423.

André, G., Garreau, P., Garnier, V., Fraunié, P., 2005. Modelled variability of the sea surface circulation in the North-western Mediterranean Sea and in the Gulf of Lions. Ocean Dynamics 55, 294-308.

Antonelli, C., Eyrolle, F., Rolland, B., Provansal, M., Sabatier, F., 2007. Suspended sediment and 137Cs fluxes during the exceptional December 2003 flood in the Rhone River, southeast France. Geomorphology 95 (3-4), 350-360.

Ardhuin, F., Bertotti, L., Bidlot, J.-R., Cavaleri, L., Filipetto, V., Lefevre, J.-M., Wittmann, P., 2007. Comparison of wind and wave measurements and models in the Western Mediterranean Sea. Ocean Engineering 34 (3-4), 526-541.

Arnoux-Chiavassa, S., Rey, V., Fraunié, P., 1999. Modelling of suspended sediment fluxes off the Rhône River mouth. Journal of Coastal Research 15 (1), 61-73.

Bassoullet, P., Le Hir, P., Gouleau, D., Robert, S., 2000. Sediment transport over an intertidal mudflat: field investigations and estimation of fluxes within the. Continental Shelf Research 20 (1213), $1635-1653$.

Blumberg, A.F., Mellor, G.L., 1987. A description of a three dimensional coastal circulation model. In: Heap, N.S. (Ed.), Three dimensional coastal ocean models, Coastal and Estuarine Sciences 4, American Geophysical Union, Washington, D.C 1-16.

Booij, N., Ris, R.C., Holthuijsen, L.H., 1999. A third-generation wave model for coastal regions. 1. Model description and validation. Journal of Geophysical Research 104 (C4), 7649-7666.

Bourrin, F., Durrieu de Madron, X., 2006. Contribution to the study of coastal rivers and associated prodeltas to sediment supply in the Gulf of Lions (N-W Mediterranean Sea). Vie \& Milieu / Life \& Environment 56 (4), 307-314. 
Bourrin, F., Durrieu de Madron, X., Heussner, S., Estournel, C., 2008a. Impact of winter dense water formation on shelf sediment erosion (evidence from the Gulf of Lions, NW Mediterranean). Continental Shelf Research 28 (15), 1984-1999.

Bourrin, F., Friend, P.L., Amos, C.L., Manca, E., Ulses, C., Palanques, A., Durrieu de Madron, X., Thompson, C.E.L., 2008b. Sediment dispersal from a typical Mediterranean flood: The Têt River, Gulf of Lions. Continental Shelf Research 28 (15), 1895-1910.

Calmet, D., Fernandez, J.M., 1990. Caesium distribution in northwest Mediterranean seawater, suspended particles and sediments. Continental Shelf Research 10 (9), 895-913.

Camenen, B., Larroudé, P., 2003. Comparison of sediment transport formulae for the coastal environment. Coastal Engineering 48 (2), 111-132.

Charmasson, S., Radakovitch, O., Arnaud, M., Bouisset, P., Pruchon, A.S., 1998. Long-core profiles of $137 \mathrm{Cs}, 134 \mathrm{Cs}, 60 \mathrm{Co}$ and $210 \mathrm{~Pb}$ in sediment near the Rhone river (Northwestern Mediterranean Sea). Estuaries 21 (3), 367-378.

Chesher, T.J., Ockenden, M., 1997. Numerical modelling of mud and sand mixture. John Wiley \& Sons, New York, USA.

Cugier, P., Le Hir, P., 2000. Three dimensional modelling of suspended matters in the eastern "baie de Seine" (English Channel, France). Comptes Rendus de l'Academie des Sciences 331, 287-294.

Cugier, P., Le Hir, P., 2002. Developpment of a 3D Hydrodynamic model for coastal ecosystem modelling. Application to the plume of the Seine River (France). Estuarine, Coastal and Shelf Science 55, 673-695.

Debreu, L., Vouland, C., Blayo, E., 2008. AGRIF: Adaptative grid refinement in Fortran. Computers \& Geosciences 34 (1), 8-13.

Drexler, T., Nittrouer, C., 2008. Stratigraphic signatures due to flood deposition near the Rhône River: Gulf of Lions, northwest Mediterranean Sea. Continental Shelf Research 28 (15), 1877-1894.

Dufau-Julliand, C., Marsaleix, P., Petrenko, A., Dekeyser, I., 2004. Three-dimensional modeling of the Gulf of Lion's hydrodynamics (northwest Mediterranean) during January 1999 (MOOGLI3 experiment) and late winter 1999: Western Mediterranean Intermediate Water's (WIW's) formation and its cascading over the shelf break. Journal of Geophysical Research 109 (C11002), C11002. DOI:10.1029/2003JC002019.

Dufois, F., 2008. Modélisation du transport particulaire dans le Golfe du Lion en vue d'une application au devenir des traceurs radioactifs issus du Rhône. Phd thesis, Université du Sud ToulonVar, France. Report ISRN/IRSN-2008/109.

Dufois, F., Garreau, P., Le Hir, P., Forget, P., 2008. Wave- and current-induced bottom shear stress distribution in the Gulf of Lions. Continental Shelf Research 28 (15), 1920-1934.

Durrieu de Madron, X., Ferre, B., Le Corre, G., Grenz, C., Conan, P., Pujo-Pay, M., Buscail, R., Bodiot, O., 2005. Trawling-induced resuspension and dispersal of muddy sediments and dissolved elements in the Gulf of Lion (NW Mediterranean). Continental Shelf Research 25 (19-20, Impact of Natural and Trawling Events on Resuspension, dispersion and fate of POLlutants (INTERPOL)), 2387-2409. 
Einstein, H., 1950. The bed-load function for sediment transportation in open channel flows. Tech. Rep. 1026, Washington, D.C., USA.

Estournel, C., Durrieu de Madron, X., Marsaleix, P., Auclair, F., Julliand, C., Vehil, R., 2003. Observations and modelisation of the winter coastal oceanic circulation in the Gulf of Lions under wind conditions influenced by the continental orography (FETCH experiment). Journal of Geophysical Research 108 (C3), 1-18.

Ferre, B., Durrieu de Madron, X., Estournel, C., Ulses, C., Le Corre, G., 2008. Impact of natural (waves and currents) and anthropogenic (trawl) resuspension on the export of particulate matter to the open ocean. Application to the Gulf of Lion (NW Mediterranean). Continental Shelf Research 28 (15), 2071-2091.

Ferre, B., Guizien, K., Durrieu de Madron, X., Palanques, A., Guillen, J., Gremare, A., 2005. Finegrained sediment dynamics during a strong storm event in the inner-shelf of the Gulf of Lion (NW Mediterranean). Continental Shelf Research 25 (19-20, Impact of Natural and Trawling Events on Resuspension, dispersion and fate of POLlutants (INTERPOL)), 2410-2427.

Fontana, C., Grenz, C., Pinazo, C., Marsaleix, P., Diaz, F., 2009. Assimilation of SeaWiFS chlorophyll data into a 3D-coupled physical-biogeochemical model applied to a freshwaterinfluenced coastal zone. Continental Shelf Research 29 (11), 1397-1409.

Gartner, J.W., 2004. Estimating suspended solids concentrations from backscatter intensity measured by acoustic Doppler current profiler in San Francisco Bay, California. Marine Geology 211, 169-187.

Gaspar, J.P., Grégoris, Y., Lefevre, J.M., 1990. A simple eddy kinetic energy model for simulations of oceanic vertical mixing: Tests at station Papa and long-term upper ocean study site. Journal of Geophysical Research 95 (C9), 16179-16193.

Gohin, F., Loyer, S., Lunven, M., Labry, C., J.M., F., Delmas, D., Huret, M., A., H., 2005. Satellitederived parameters for biological modelling in coastal waters : Illustration over the eastern continental shlef of the bay of Biscay. Remote Sensing of Environment 95 (1), 29-46.

Got, H., Aloisi, J.C., 1990. The Holocene sedimentation on the Gulf of Lions margin: a quantitative approach. Continental Shelf Research 10 (9-11), 841-855.

Guillén, J., Bourrin, F., Palanques, A., Durrieu de Madron, X., Puig, P., Buscail, R., 2006. Sediment dynamics during wet and dry storm events on the Tet inner shelf (SW Gulf of Lions). Marine Geology 234 (1-4, EUROSTRATAFORM VOL. 1: Source to Sink Sedimentation on the European Margin), 129-142.

Hossain, S., Eyre, B., Mcconchie, D., 2001. Suspended Sediment Transport Dynamics in the Subtropical Micro-tidal Richmond River Estuary, Australia. Estuarine, Coastal and Shelf Science 52 (5), 529-541.

Jestin, H., Bassoullet, P., Le Hir, P., L'Yavanc, J., Degres, Y., 1998. Development of ALTUS, a high frequency acoustic submersible recording altimeter to accurately monitor bed elevation and quantify deposition or erosion of sediments. OCEANS'98 Conference Proceedings, 189-194

Lansard, B., 2005. Distribution et remobilisation du plutonium dans les sédiments du prodelta du Rhône (Méditerranée nord-occidentale). Phd thesis, Université de la Méditerranée. Aix-Marseille II, France. Report IRSN-SESURE 2005-12. 
Lansard, B., Charmasson, S., Gasco, C., Anton, M.P., Grenz, C., Arnaud, M., 2007. Spatial and temporal variations of plutonium isotopes $(238 \mathrm{Pu}$ and $239,240 \mathrm{Pu})$ in sediments off the Rhone River mouth (NW Mediterranean). Science of The Total Environment 376 (1-3), 215-227.

Lansard, B., Grenz, C., Charmasson, S., Schaaff, E., Pinazo, C., 2006. Potential plutonium remobilisation linked to marine sediment resuspension: First estimates based on flume experiments. Journal of Sea Research 55 (1), 74-85.

Lazure, P., Dumas, F., 2007. An external-internal mode coupling for a 3D hydrodynamical Model for Applications at Regional Scale (MARS3D). Advances in water Ressources 31 (2), 233-250. DOI:10.1016/j.advwatres.2007.06.010

Le Hir, P., Cann, P., Waeles, B., Jestin, H., Bassoulet, P., 2008. Erodibility of natural sediments: experiments on sand/mud mixtures from laboratory and field erosion tests. Sediment and Ecohydraulics: INTERCOH 2005, in Proceedings in Marine Science Nº, Elsevier 137-153.

Le Hir, P., Ficht, A., Silva Jacinto, R., Lesueur, P., Dupont, J.-P., Lafite, R., Brenon, I., Thouvenin, B., Cugier, P., 2001. Fine sediment transport and accumulations at the mouth of the Seine Estuary (France). Estuaries 24 (6B), 950-963.

Leendertse, J.J., 1970. A water-quality simulation model for well-mixed estuaries and coastal seas. Principle of Computation, The Rand Corporation 1 (RM-6230).

Leonard, B.P., 1979. A stable and accurate convective modelling procedure based on quadratic upstream interpolation. Computer Methods in Applied Mechanics and Engineering 19, 59-98.

Longuet-Higgins, M.S., Stewart, R.W., 1960. Changes in the form of short gravity waves on long waves and tidal currents. Journal of Fluid Mechanics 8, 565-583.

Longuet-Higgins, M.S., Stewart, R.W., 1962. Radiation stresses and mass transport in surface gravity waves with application to surf beats. Journal of Fluid Mechanics 13, 481-504.

Maillet, G., 2005. Relations sédimentaires récentes et actuelles entre un fleuve et son delta en milieu microtidal : Exemple de l'embouchure du Rhône. Phd thesis, Université Aix-Marseille 1, France.

Maillet, G., Vella, C., Berné, S., Friend, P.L., Amos, C.L., Fleury, T.J., Normand, A., 2006. Morphological changes and sedimentary processes induced by the December 2003 flood event at the present mouth of the Grand Rhône River (southern France). Marine Geology 234 (1-4), 159-177.

Marion, C., Dufois, F., Vassas, C., Arnaud, M., 2010. In situ record of sedimentary processes near the Rhône River mouth during winter events (Gulf of Lions, Mediterranean Sea). Continental Shelf Research 30 (9), 1095-1107

McKee, B.A., Aller, R.C., Allison, M.A., Bianchi, T.S., Kineke, G.C., 2004. Transport and transformation of dissolved and particulate materials on continental margins influenced by major rivers: benthic boundary layer and seabed processes. Continental Shelf Research 24 (7-8), 899-926.

Meyer-Peter, E., Müller, R., 1948. Formulas for bed-load transport. Report on the 2nd Meeting International Association Hydraulic Structure Research, Stockholm, Sweden, 39-64.

Millot, C., 1990. The Gulf of Lions' hydrodynamics. Continental Shelf Research 10 (9-11), 885-894. 
Miralles, J., Arnaud, M., Radakovitch, O., Marion, C., Cagnat, X., 2006. Radionuclide deposition in the Rhone River Prodelta (NW Mediterranean sea) in response to the December 2003 extreme flood. Marine Geology 234 (1-4, EUROSTRATAFORM VOL. 1: Source to Sink Sedimentation on the European Margin), 179-189.

Miralles, J., Radakovitch, O., Aloisi, J.-C., 2005. 210Pb sedimentation rates from the Northwestern Mediterranean margin. Marine Geology 216 (3), 155-167.

Mitchener, H., Torfs, H., 1996. Erosion of mud/sand mixtures. Coastal Engineering 29 (1-2), 1-25.

Naudin, J.-J., Cauwet, G., 1997. Transfert mechanisms and biogeochimical implications in the bottom nepheloid layer. A case study of the coastal zone off the Rhône River (France). Deep Sea Research 44 (3-4), 551-575.

Naudin, J.-J., Cauwet, G., M.J., C.-D., Deniaux, B., Devenon, J.-L., Pauc, H., 1997. River discharge and wind influence upon particulate transfer at the land-ocean interaction : Case Study of the Rhône River plume. Estuarine, Coastal and Shelf Science 45, 303-316.

Noël, M.-H., 1996. Le plutonium comme traceur du transfert et de l'accumulation des apports particulaires du Rhône en Méditerranée Nord Occidentale. Phd thesis, Université de Paris 12, France.

Palanques, A., Durrieu de Madron, X., Puig, P., Fabres, J., Guillen, J., Calafat, A., Canals, M., Heussner, S., Bonnin, J., 2006. Suspended sediment fluxes and transport processes in the Gulf of Lions submarine canyons. The role of storms and dense water cascading. Marine Geology 234 (1-4, EUROSTRATAFORM VOL. 1: Source to Sink Sedimentation on the European Margin), 43-61.

Palanques, A., Guillén, J., Puig, P., Durrieu de Madron, X., 2008. Storm-driven shelf-to-canyon suspended sediment transport at the southwestern Gulf of Lions. Continental Shelf Research 28 (15), 1947-1956.

Palanques, A., Puig, P., Guillén, J., de Madron, X.D., Latasa, M., Scharek, R., Martin, J., 2011. Effects of storm events on the shelf-to-basin sediment transport in the southwestern end of the Gulf of Lions (Northwestern Mediterranean). Natural Hazards and Earth System Sciences 11, 843-850.

Panagiotopoulos, I., Voulgaris, G., Collins, M.B., 1997. The influence of clay on the threshold of movement of fine sandy beds. Coastal Engineering 32 (1), 19-43.

Parker, G., 1990. Surface-based bed-load transport relation on gravel rivers. Journal of Hydraulic Research 28 (4), 417-436.

Pauc, H., 1970. Contribution à l'étude dynamique et sédimentologique des suspensions solides au large de l'embouchure du Grand Rhône (Grau de Roustan). Phd thesis, Université de Montpellier, France.

Phillips, O.M., 1977. The dynamics of the upper ocean. Cambridge University Press, London, UK.

Pont, D., Simonnet, J.P., Walter, V., 2002. Medium-term Changes in Suspended Sediment Delivery to the Ocean: Consequences of Catchement Heterogeneity and River Management (Rhône River, France). Estuarine, Coastal and Shelf Science 54, 1-18.

Radakovitch, O., Cherry, R.D., Heussner, S., 1999. 210Pb and 210Po: tracers of particle transfer on the Rhone continental margin (NW Mediterranean). Deep Sea Research Part I: Oceanographic Research Papers 46 (9), 1539-1563. 
Ris, R.C., Booij, N., Holthuijsen, L.H., 1999. A third-generation wave model for coastal regions. 2. Verification. Journal of Geophysical Research 104 (C4), 7667-7681.

Rolland, B., 2006. Transfert des radionucléides par voie fluviale : conséquences sur les stocks sédimentaires rhodaniens et les exports vers la Méditerranée. Phd thesis, Université d'Aix-Marseille, France.

Roussiez, V., Aloisi, J.-C., Monaco, A., Ludwig, W., 2005. Early muddy deposits along the Gulf of Lions shoreline: A key for a better understanding of land-to-sea transfer of sediments and associated pollutant fluxes. Marine Geology 222-223 (Mediterranean Prodelta Systems), 345-358.

Roussiez, V., Ludwig, W., Monaco, A., Probst, J.-L., Bouloubassi, I., Buscail, R., Saragoni, G., 2006. Sources and sinks of sediment-bound contaminants in the Gulf of Lions (NW Mediterranean Sea): A multi-tracer approach. Continental Shelf Research 26 (16), 1843-1857.

Schaaff, E., 2003. Dynamique de la matière particulaire à l'interface eau-sédiment en zone côtière : approches expérimentales et modélisation. Phd thesis, Université de la Méditerranée. Aix-Marseille II, France.

Schaaff, E., Grenz, C., Pinazo, C., 2002. Erosion of particulate inorganic and organic matter in the Gulf of Lion. Comptes Rendus Geoscience 334 (15), 1071-1077.

Sherwood, Book, J.W., Carniel, S., Cavaleri, L., Chiggiato, J., Das, H., Doyle, J.D., Harris, C.K., Niedoroda, A.W., Perkins, H., Poulain, P.M., Pullen, J., Reed, C.W., Russo, A., Sclavo, M., Signell, R.P., Traykovski, P., Warner, J.C., 2004. Sediment dynamics in the Adriatic sea investigated with coupled models. Oceanography 17 (4), 58-69.

Smagorinsky, J., 1963. General circulation experiments with the primitive equations.1-The basic experiment. Monthly Weather Review 91, 99-165.

Soulsby, R.L., 1997. Dynamics of marine sands. A manual for practical applications. Thomas Telford, London, UK.

Swart, D.H., 1974. Offshore sediment transport and equilibrium beach profiles. Delft Hydraulics Laboratory publication, 131, Delft, Netherlands.

Tessier, C., 2006. Caractérisation et dynamique des turbidités en zône côtière : l'exemple de la région marine Bretagne Sud. Phd thesis, Université Bordeaux 1, France.

Tessier, C., Le Hir, P., Lurton, X., Castaing, P., 2008. Estimation of suspended sediment concentration from backscatter intensity of Acoustic Doppler Current Profiler. Comptes Rendus Geosciences 340 (1), 57-67.

The Medatlas Group: Gaillard, P., Ravazzola, P., Kontolios, C., Arrivet, L., Athanassoulis, G.A., Stefanakos, C.N., Gerostathis, T.P., Cavaleri, L., Bertotti, L., Sclavo, M., Ramieri, E., Dentone, L., Noel, C., Viala, C., Lefevre, J.M., 2004. Wind and Wave Atlas of the Mediterranean Sea. 420p.

Thill, A., 1999. Agrégation des particules : structure, dynamique et simulation. Application au cas d'un écoulement stratifié : l'estuaire du Rhône. Phd thesis, Université d'Aix-Marseille, France. 
Thill, A., Moustier, S., Garnier, J.-M., Estournel, C., Naudin, J.-J., Bottero, J.-Y., 2001. Evolution of particle size and concentration in the Rhone river mixing zone: influence of salt flocculation. Continental Shelf Research 21, 2127-2140.

Thomas, A.J., 1997. Input of artificial radionuclides to the Gulf of Lions and tracing the Rhône influence in marine surface sediments. Deep Sea Research II 44 (3-4), 577-595.

Thorn, M.F.C., 1981. Physical processes of siltation in channels. Proceedings of the Conference on Hydraulic Modelling Applied to Maritime Engineering Problems. Institution of Civil Engineers, London, UK, 47-55.

Ulses, C., 2006. Dynamique océanique et transport de la matière particulaire dans le Golfe du Lion : Crue, tempête et période hivernale. Phd thesis, Université Paul Sabatier, Toulouse, France.

Ulses, C., Estournel, C., Durrieu de Madron, X., Palanques, A., 2008. Suspended Sediment Transport in the Gulf of Lion (NW Mediterranean): Impact of Extreme Storms and Floods. Continental Shelf Research 28 (15), 2048-2070.

van der Wal, D., Herman, P.M.J., Wielemaker-van den Dool, A., 2005. Characterisation of surface roughness and sediment texture of intertidal flats using ERS SAR imagery. Remote Sensing of Environment 98, 96-109.

van Ledden, M., Wang, Z.B., 2001. Sand-mud morphodynamics in an estuary. Proceedings of the 2nd Symposium on River, Coastal and Estuarine Morphodynamics Conference, Obihiro, Japan, 505-514.

van Leussen, W., 1994. Estuarine macroflocs : their role in fine grained sediment transport. PhD Thesis, University of Utrecht, Utrecht. 488 p.

van Rijn, L.C., 1984. Sediment transport : part III : bed forms and alluvial roughness. Journal of the Hydraulic Ingineering, Proceedings of the American Society of Civil Engineers 110 (12), 1733-1754.

Waeles, B., 2005. Modélisation morphodynamique de l'embouchure de la Seine. Phd thesis, Université de Caen, France.

Waeles, B., Hir, P.L., Lesueur, P., 2008. A 3D morphodynamic process-based modelling of a mixed sand/mud coastal environment: the Seine estuary, France. Sediment and Ecohydraulics: INTERCOH 2005, in Proceedings in Marine Science Nº , Elsevier, 477-498.

Walsh, J.P., Nittrouer, C.A., 2009. Understanding fine-grained river-sediment dispersal on continental margins. Marine Geology 263 (1-4), 34-45.

Whitehouse, R., Soulsby, R.L., Roberts, W., Mitchener, H., 2000. Dynamics of estuarine muds. Thomas Telford, London, UK.

Wu, W., Wang, S.S.Y., Jia, Y., 2000. Nonuniform sediment transport in alluvial rivers. Journal of Hydraulic Research 38 (6), 427-434.

Figure 1: Study site and sediment facies (\% sand fraction) in the coarse resolution model domain GOL and in the fine resolution model domain PRODELTA. The boundaries of the 
first nested SWAN (into WW3) are shown as grey dotted boxes. The boundaries of the finer nested SWAN and MARS-3D domain are also shown as black boxes. The white star shows the location of the La Balancelle station. Isobaths 20, 60, 160, 200 and 2000 are plotted.

Figure 2: Hydrodynamics and meteorological conditions at La Balancelle Station. (a) Measured Rhone River discharge, (b) wind (intensity and direction) according to the MétéoFrance ALADIN reanalysis, (c) significant wave height hs, (d) mean wave period Tm, (e) current sampled every 6 hours at three different levels within the water column $(2,9$ and 16 metres above the bottom (mab)), (f) and (g) respectively the direction (Dir) and magnitude (U) of the depth averaged (from 2 to 16 mab) velocity. From (c) to (g) ADCP measures are plotted in red, while modelled values are plotted in blue.

Figure 3: Sediment dynamics at La Balancelle station. (a) Modelled total bed shear stress $\tau_{s f}$ (black) and wave induced bed shear stress $\tau_{w}$ (grey). SPM concentration in the water column estimated by ADCP (b) and modelled (c). (d) SPM concentration at 2 mab estimated by ADCP (black) and modelled (grey). (e) bed variation measured with the ALTUS altimeter (black) and modelled (grey). For (c), the signal near the surface (10\% of the water height) was removed as the air-sea interface resulted in a high backscattering level. Cells where velocities were not determined were also removed.

Figure 4: Cumulative suspended sediment flux at $2 \mathrm{mab}$ (a) and depth-averaged (from 2 to 16 mab) cumulative suspended sediment flux (b) during the SCOPE experiment. In situ measurements are in black and modelled estimates in grey. The dates of the storms are indicated between the two graphs. The peaks of the two storms from the south-east occurred on the $20^{\text {th }}$ of November 2007 at midnight and on the $4^{\text {th }}$ of January 2008 at 6 am. 
Figure 5: (a) Modelled significant wave height $(\mathrm{m})($ shaded areas) and wind ( $\mathrm{m} / \mathrm{s})($ arrows), and (b) modelled bed shear stress $\tau_{s f}\left(\mathrm{~N} / \mathrm{m}^{2}\right)$ the $20^{\text {th }}$ of November 2007 at midnight. Isobaths 20, 50, 100 and $160 \mathrm{~m}$ are shown.

Figure 6: Surface SPM concentration (mg/l) estimated by MODIS (on the left) and modelled (on the right) at noon for the $23^{\text {rd }}$ November 2007 (a)(b) and the $25^{\text {th }}$ November 2007 (c)(d). Météo-France Aladin winds are also represented (arrows). The peak of the storm from the south-east occurred on the $20^{\text {th }}$ November 2007 at midnight.

Figure 7: Mean surface SPM concentrations (mg/l) estimated by MODIS during the experiment (a) and computed by the model during the corresponding days (b). (c) Correlation COR (\%) and (d) relative error SI (\%) between satellite data and model results for surface SPM concentrations.

Figure 8: Modelled particulate matter budget for sand and mud throughout the PRODELTA domain during the SCOPE experiment.

Figure 9: Situation simulated for the $20^{\text {th }}$ November 2007 at midnight. SPM (sands + mud) concentration (colour scale) and currents (arrows) at the surface (ab) and at the bottom (cd). The 20,50, 100 and $160 \mathrm{~m}$ isobaths are shown.

Figure 10: Variations in mud levels (ab) and sand levels (cd) during the whole simulation period (deposition $>0$ and erosion $<0$ ). 20, 50, 100 and $160 \mathrm{~m}$ isobaths are shown. 
Figure 11: Situation on $20^{\text {th }}$ November 2007 at midnight. (a) Depth-averaged current and (b) wave-induced component of the depth-averaged current $(\mathrm{m} / \mathrm{s})$ computed by the model. 20,50 and $100 \mathrm{~m}$ isobaths are shown.

Figure 12: Scatter plot of $10 \log _{10}(\mathrm{SPM}(\mathrm{NTU})-7)$ estimated by the turbidimeter versus the relative volume backscattering index $\operatorname{IV}_{r}(\mathrm{~dB})$ given by the $\mathrm{ADCP}$. The equivalence of the values on the $y$-axis is given in NTU on the right-side of the axis. The grey dots were not used for calibration (grey line).

Figure 13: Time series of SPM (NTU) measurements from the optical turbidimeter (grey) and from ADCP acoustical measurements (black). The grey area corresponds to the period that was not used for calibration (grey dots on Figure 12).

Table 1: Statistical parameters (detailed in appendix C) of the comparison between modelled variables and variables measured in situ at the mooring station. Statistics over the whole time series are reported in plain and over energetic periods $\left(h_{s}>2 \mathrm{~m}\right)$ in bold. $U$ and Dir are the magnitude and direction of the depth averaged velocity (from 2 mab to 16 mab). SPM is the suspended sediment concentration at 2 mab. N.B.: for direction Dir, the Scatter Index (SI) has no sense.

Table 2: Sediment budget during the SCOPE experiment (Mt). Mud I corresponds to mud initially present on the bed. Mud II corresponds to mud discharged by the Rhone River. Sands include the two sand classes. 


\begin{tabular}{|c|c|c|c|c|}
\hline & COR & BIAS & $R M S E$ & $S I$ \\
\hline$U(m / s)$ & $0.47 / 0.64$ & $-0.07 / 1.2$ & $6.1 / 7.4$ & $0.54 / 0.35$ \\
\hline $\operatorname{Dir}\left(^{\circ}\right)$ & $0.73 / 0.76$ & $17.1 /-4.6$ & $87.8 / 51.7$ & \\
\hline$h_{s}(m)$ & $0.94 / 0.81$ & $0.01 / 0.01$ & $0.23 / 0.39$ & $0.21 / 0.12$ \\
\hline$T_{m}(s)$ & $0.81 / \mathbf{0 . 6 7}$ & $-0.44 /-0.23$ & $0.80 / 0.39$ & $0.19 / 0.07$ \\
\hline$P M(m g / l)$ & $0.76 / 0.66$ & $0.98 / 9.6$ & 12.3/33.9 & $0.67 / 0.63$ \\
\hline
\end{tabular}

$-49-$ 


\begin{tabular}{|c|c|c|c|}
\hline & Mud I & Mud II & Sands \\
\hline \multicolumn{4}{|c|}{ Discharge } \\
\hline Rhone River & 0 & +0.55 & +0.055 \\
\hline \multicolumn{5}{|c|}{ Sediment storage } \\
\hline PRODELTA domain & -2.7 & +0.17 & -1.4 \\
\hline GOL domain & -6.1 & +0.30 & +0.06 \\
\hline \multicolumn{2}{|c|}{ Export } & +0.33 & +1.4 \\
\hline PRODELTA domain & +2.7 & +0.25 & 0 \\
\hline GOL domain & +6.1 & & \\
\hline
\end{tabular}

A 3D sediment transport model is developed

The hydro-sedimentary in situ SCOPE experiment is presented

The model is validated using the various in situ data

The impact of winter storms over the Rhone prodelta is assessed 


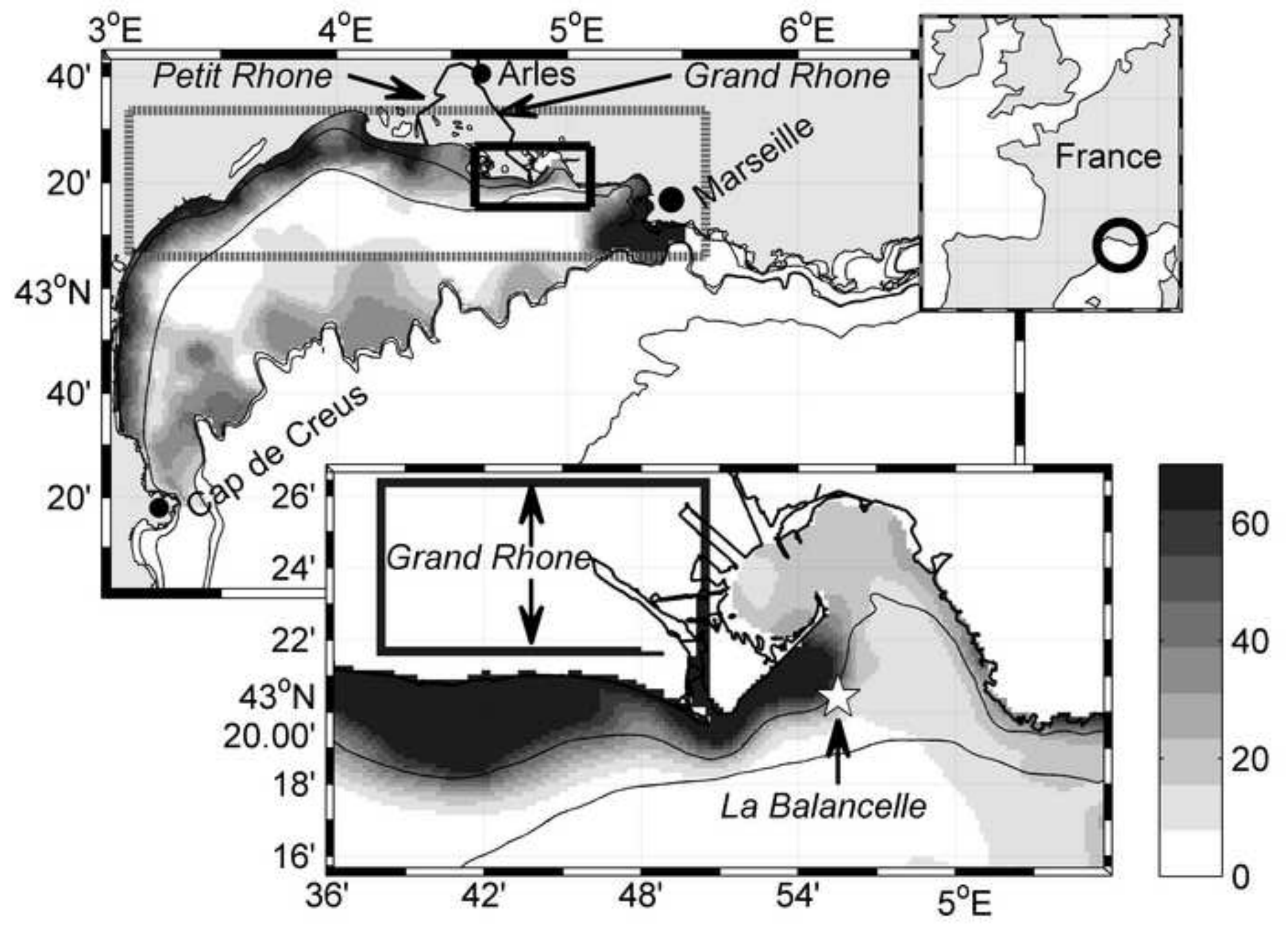




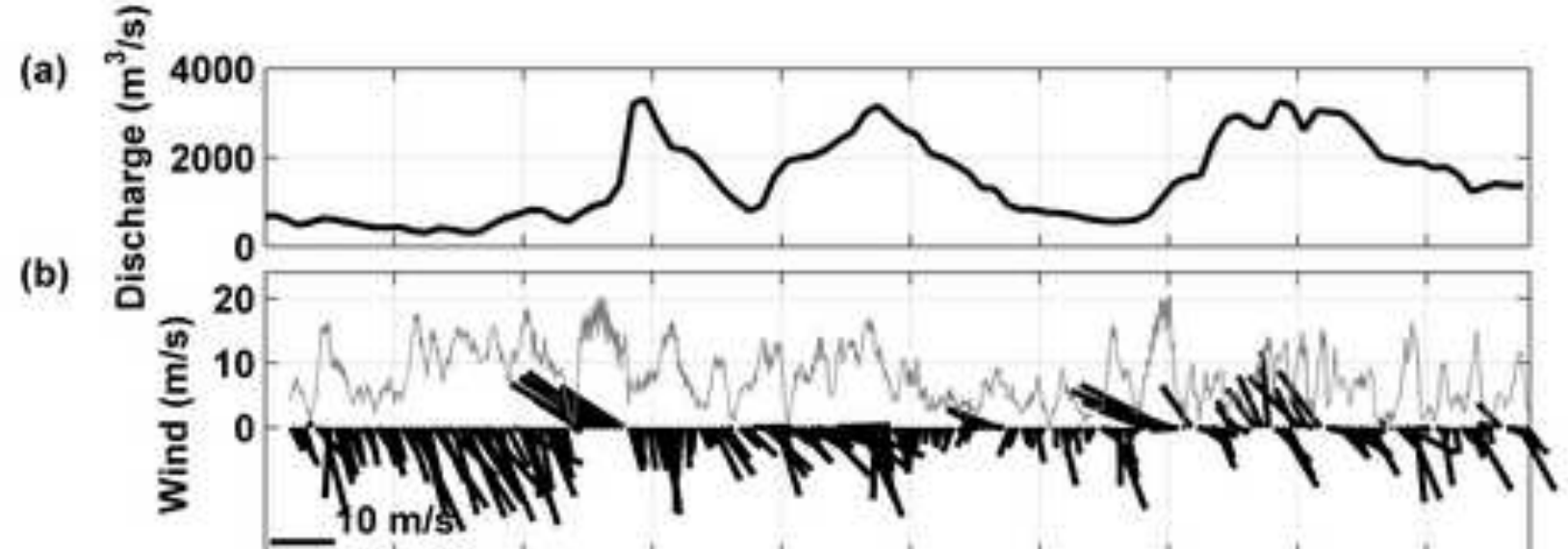

(c)

(e)

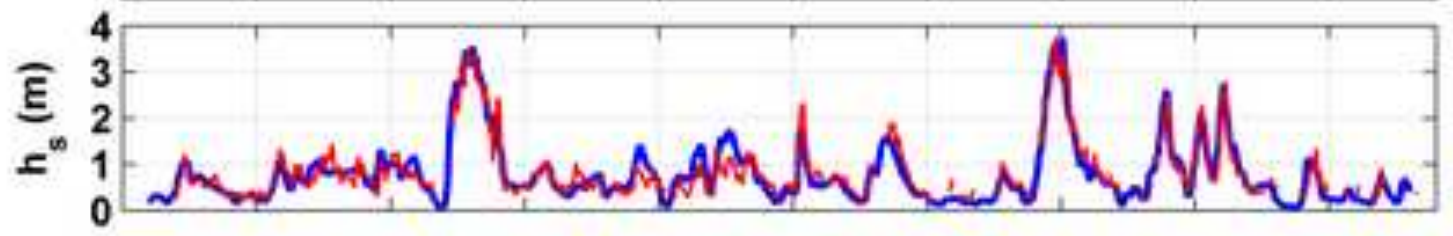

(d)
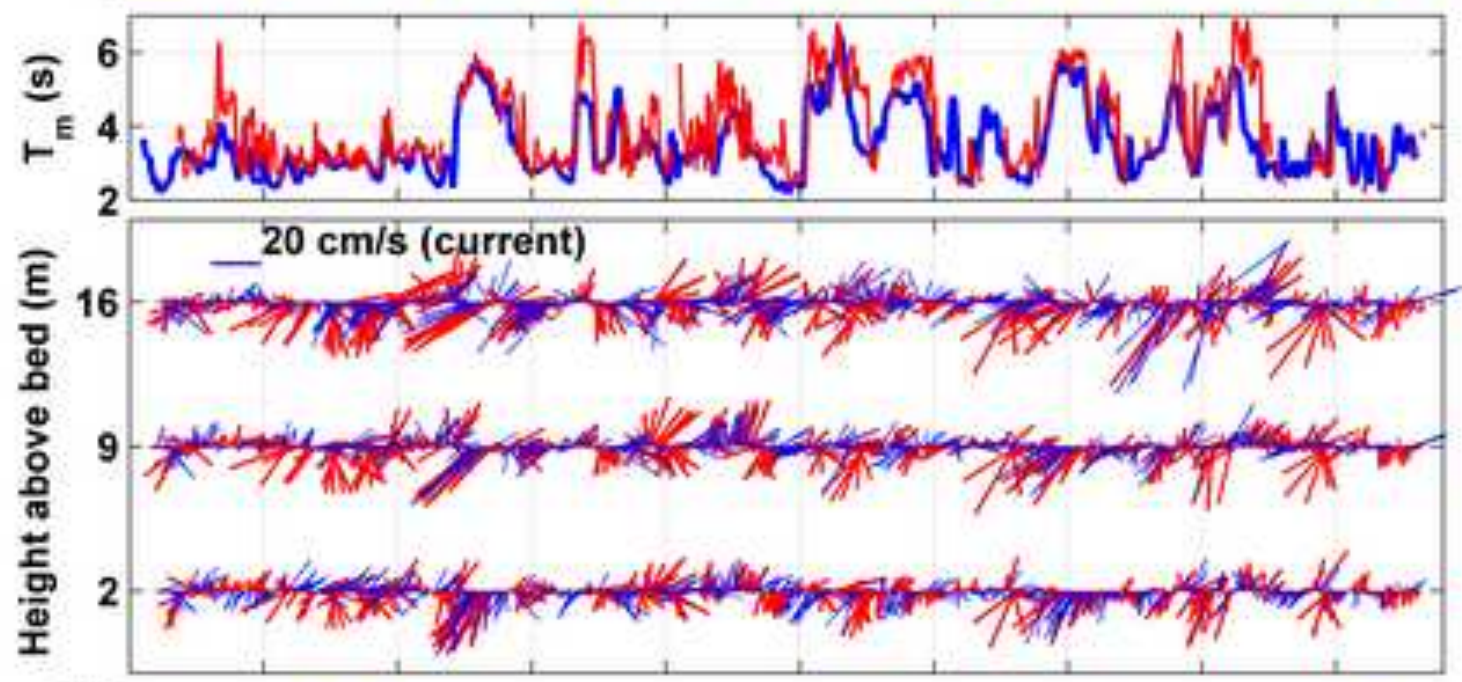

(f)

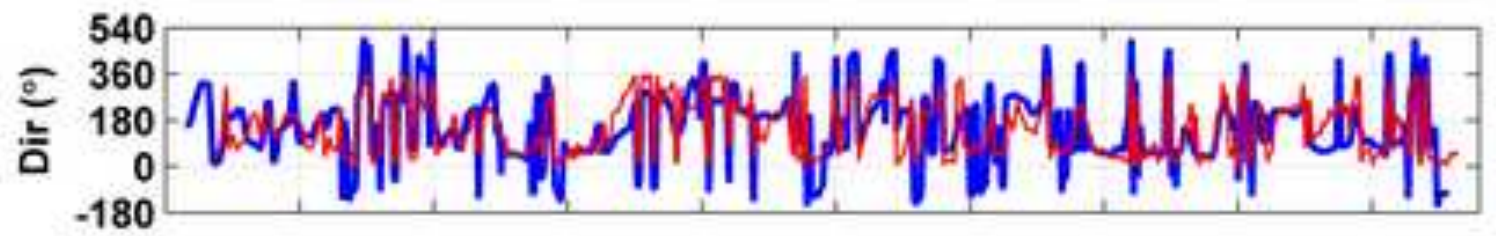

(g)

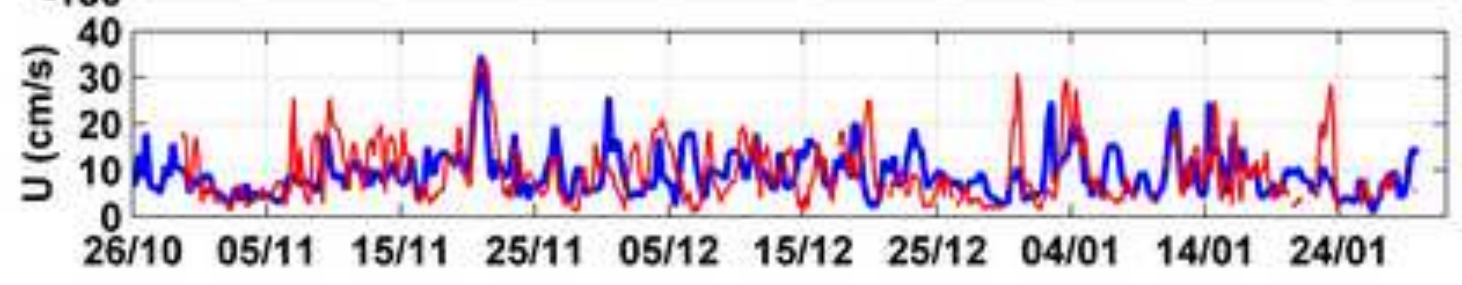


(a)

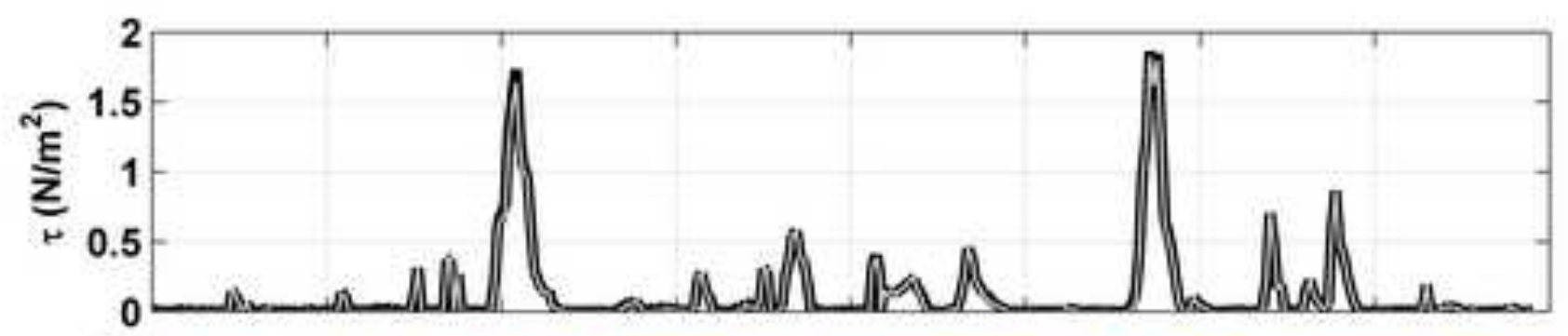

(b)

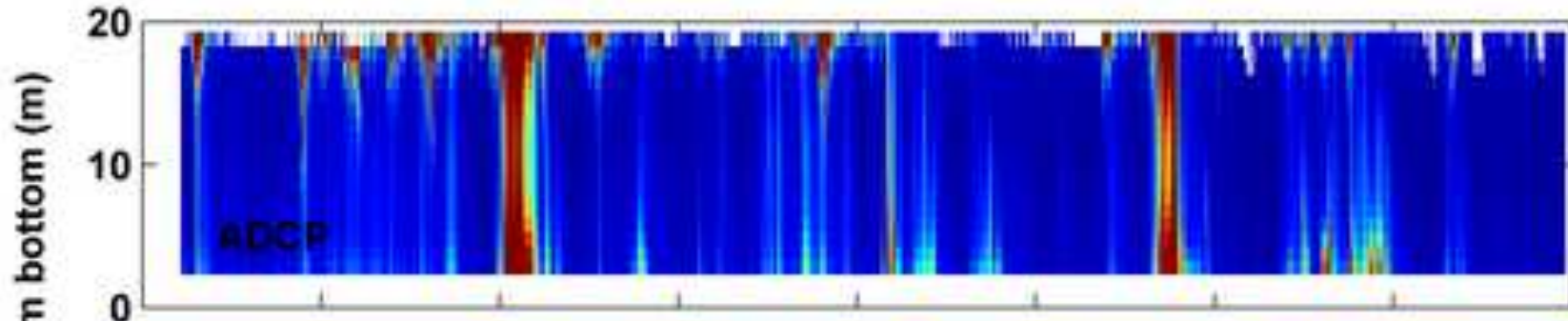

(c)

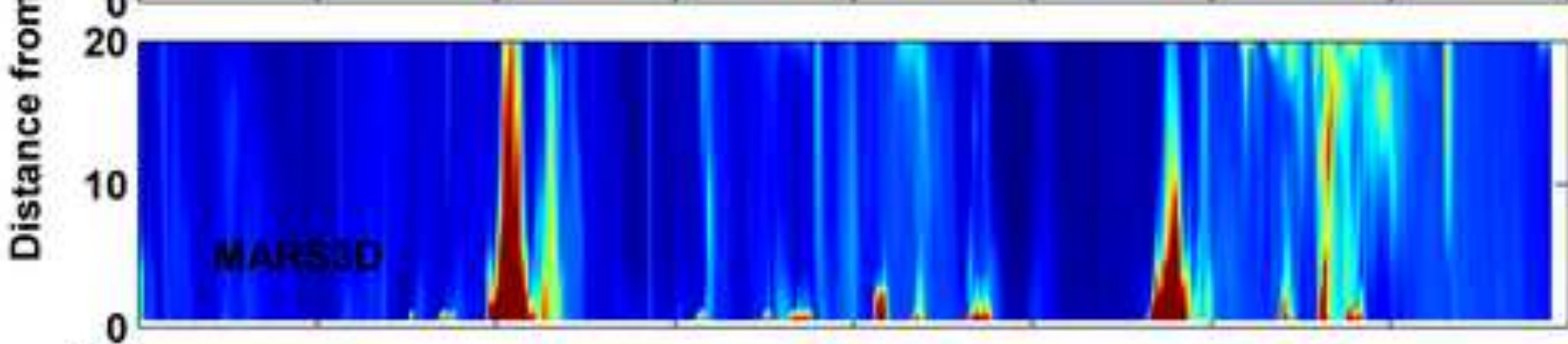

SPM(mg/l)

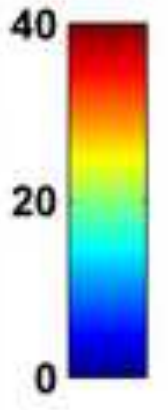

(d)

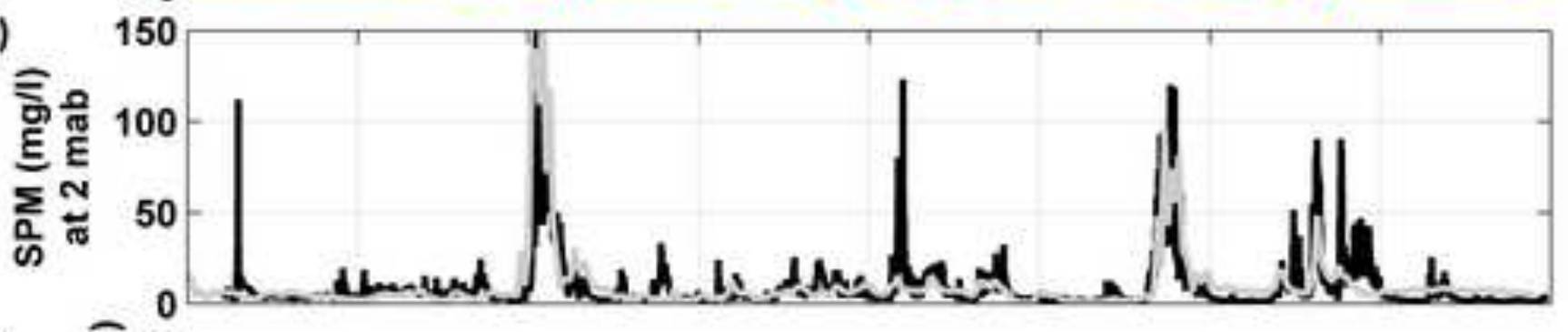

(e) $\widehat{E}^{2}$.

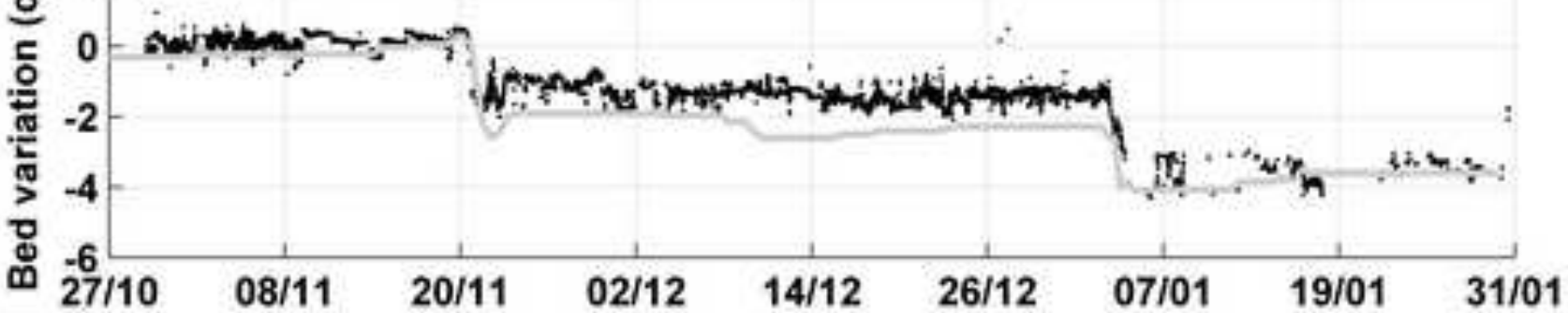


(a)

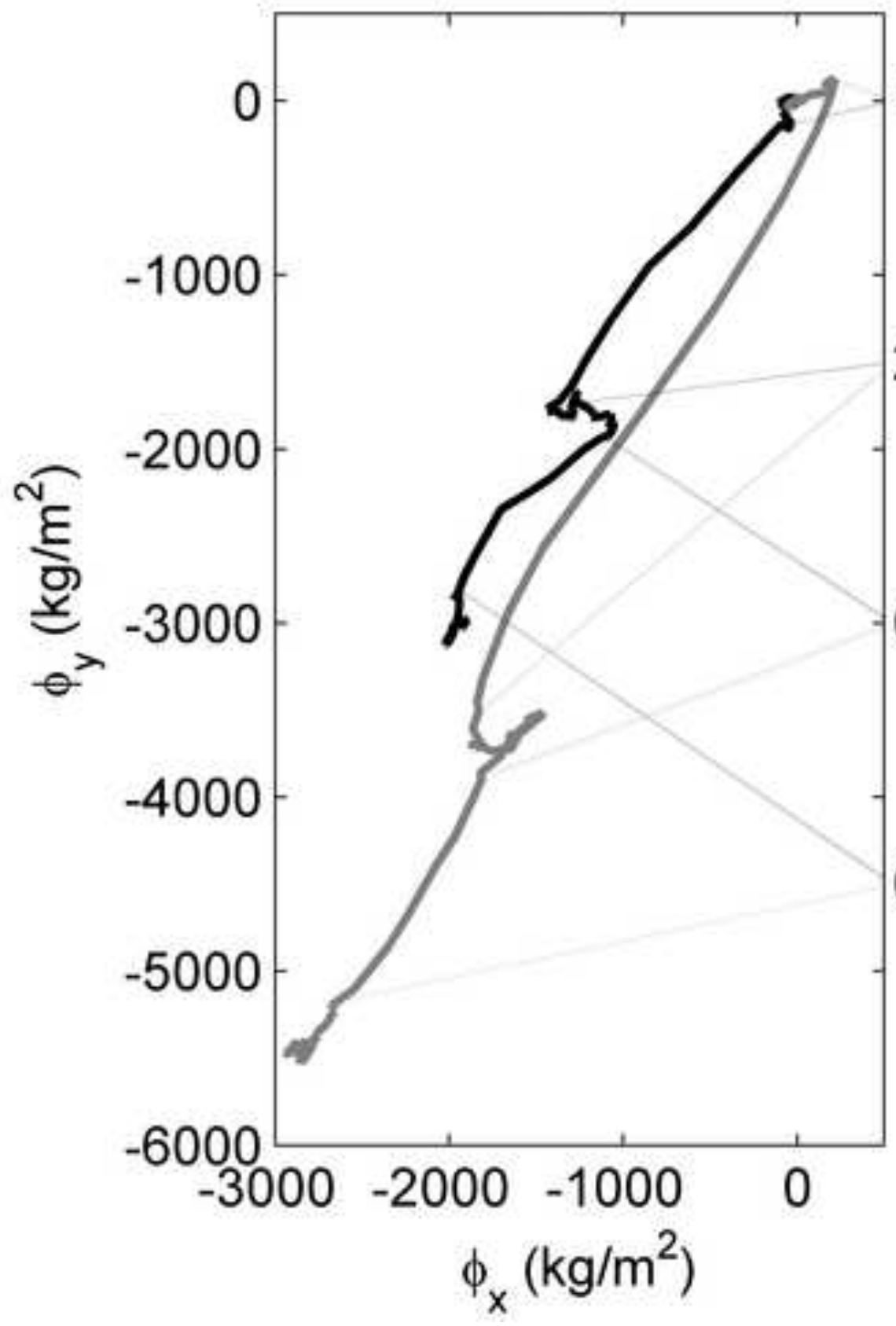

(b)

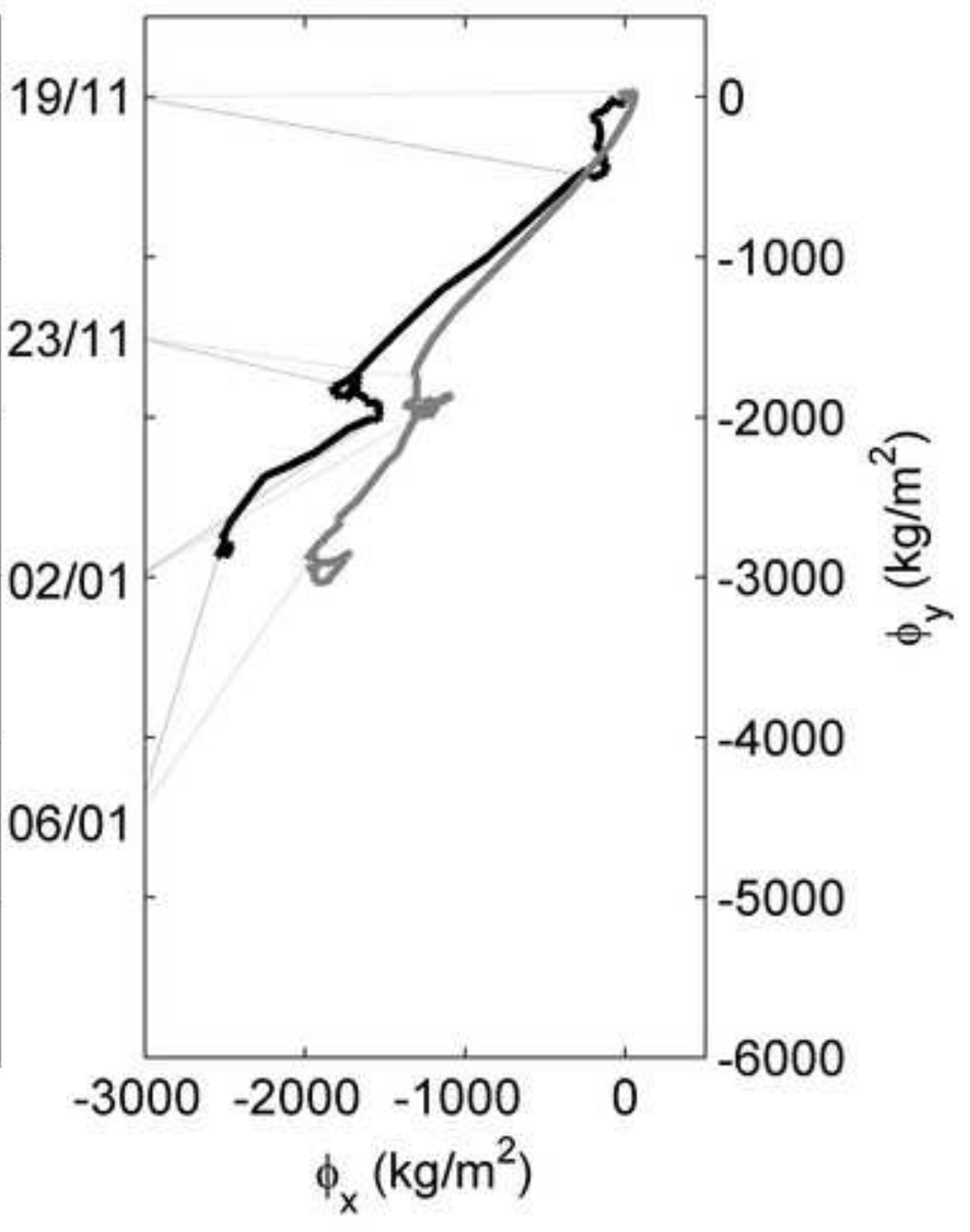



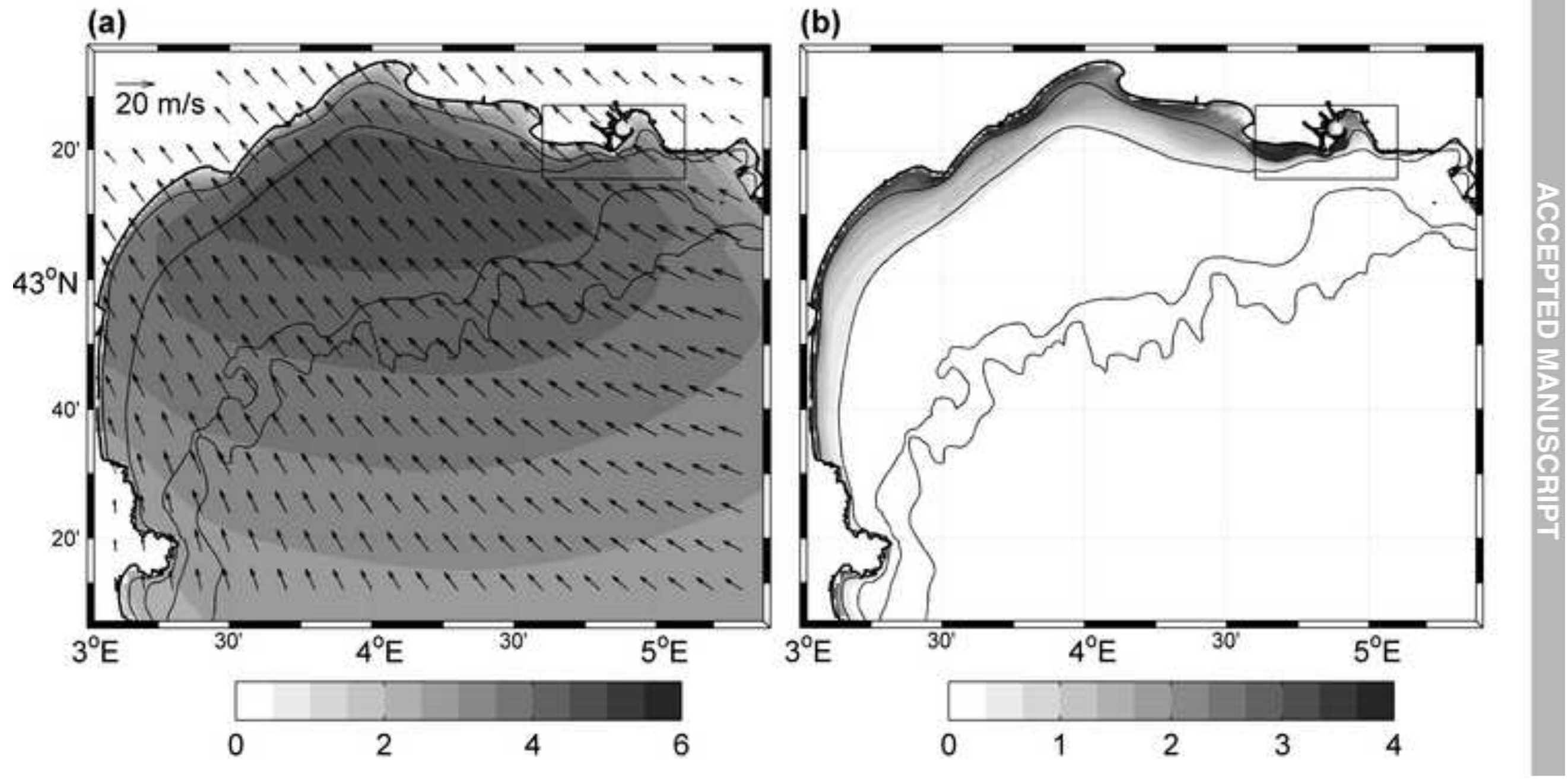
(a) MODIS

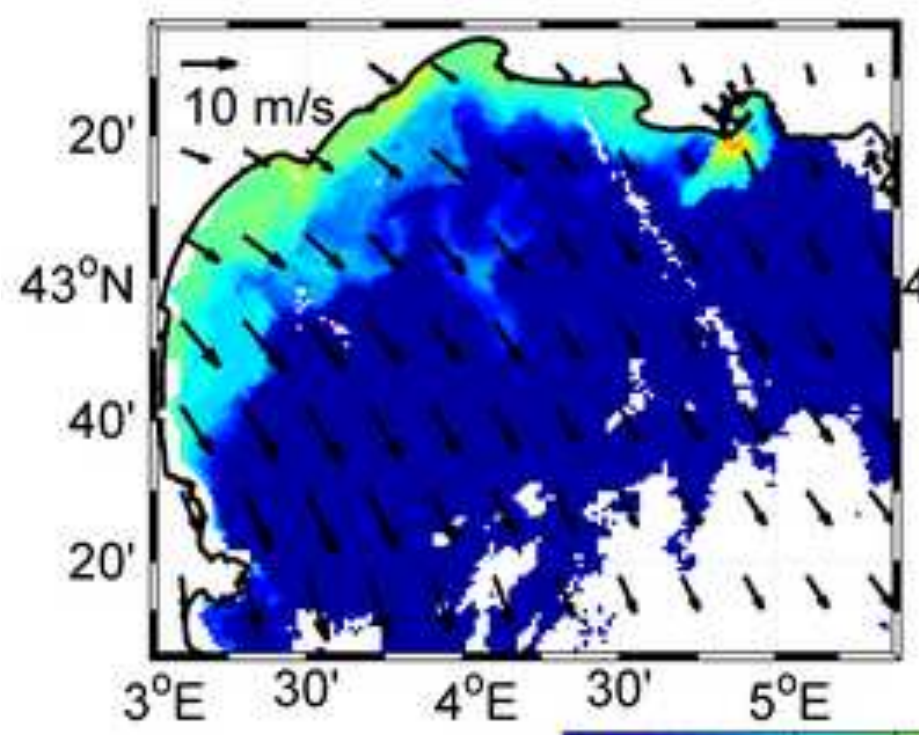

$23 / 11 / 2007$

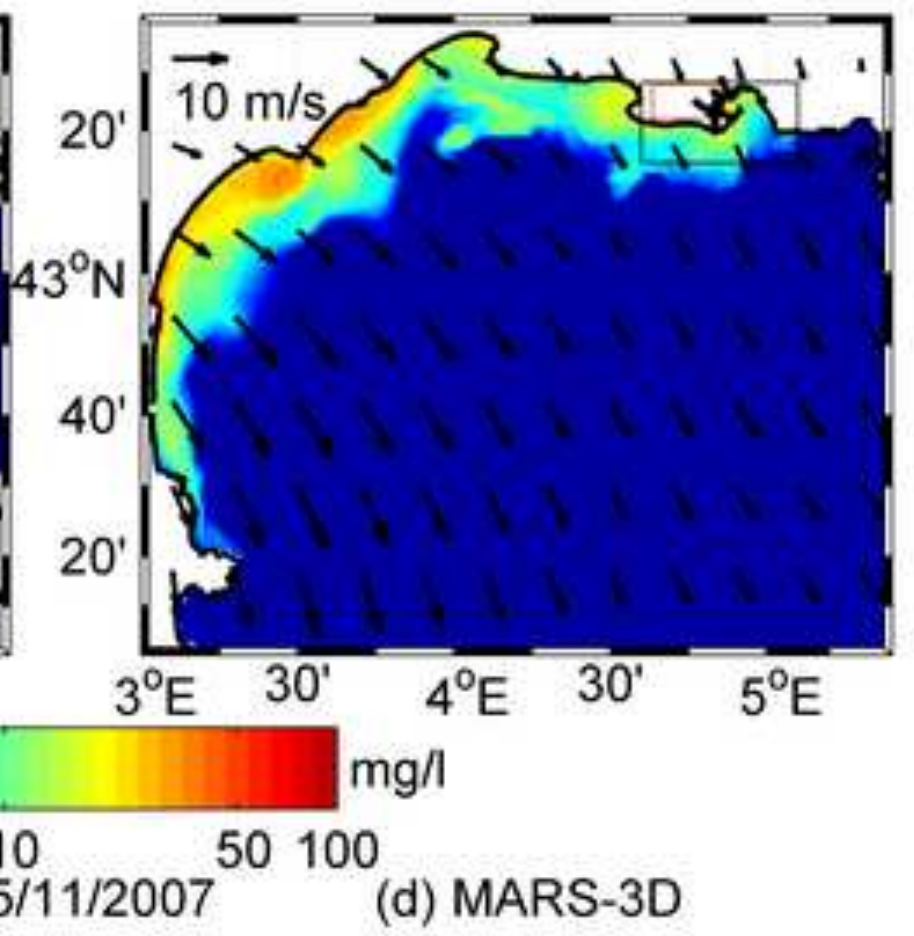

$\mathrm{mg} / \mathrm{l}$

(b) MARS-3D
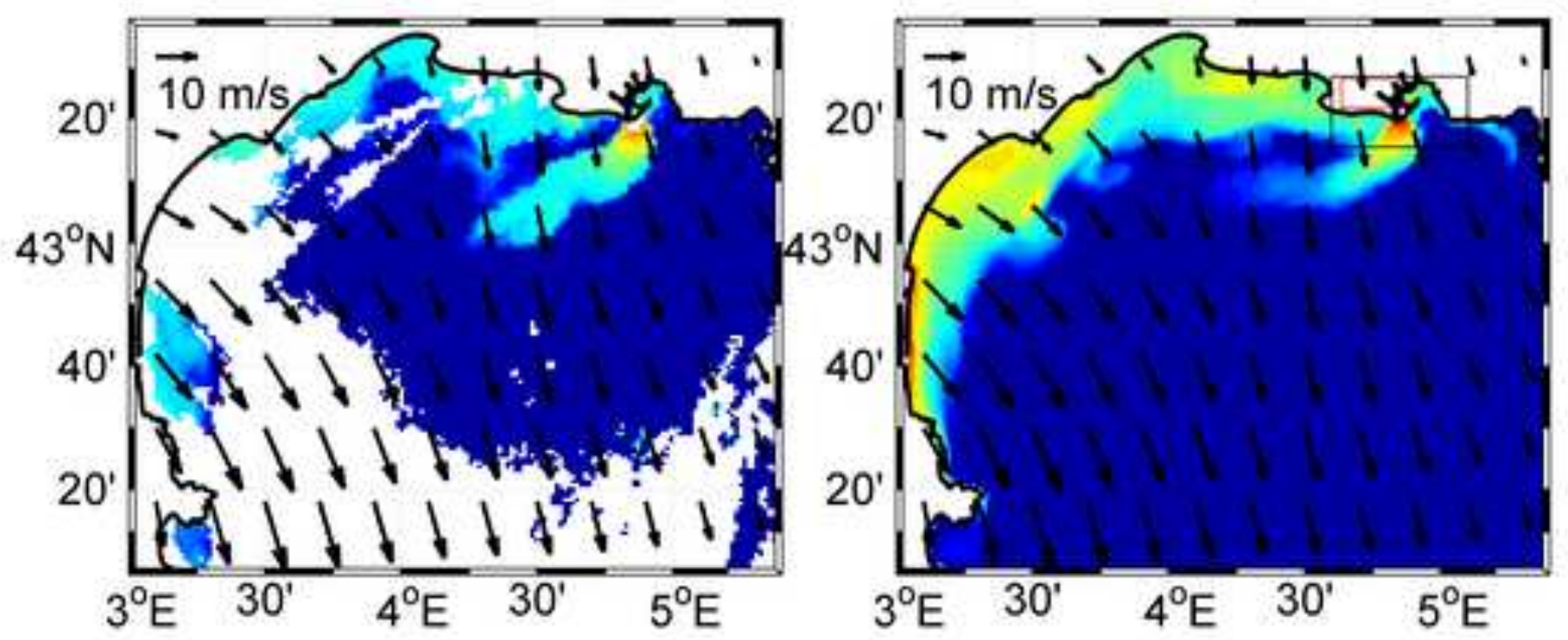
(a) MODIS (mg/l) $\quad 0 \quad 5 \quad 10 \quad 15$

(b) MARS-3D (mg/l) $\quad 5 \quad 10 \quad 15$
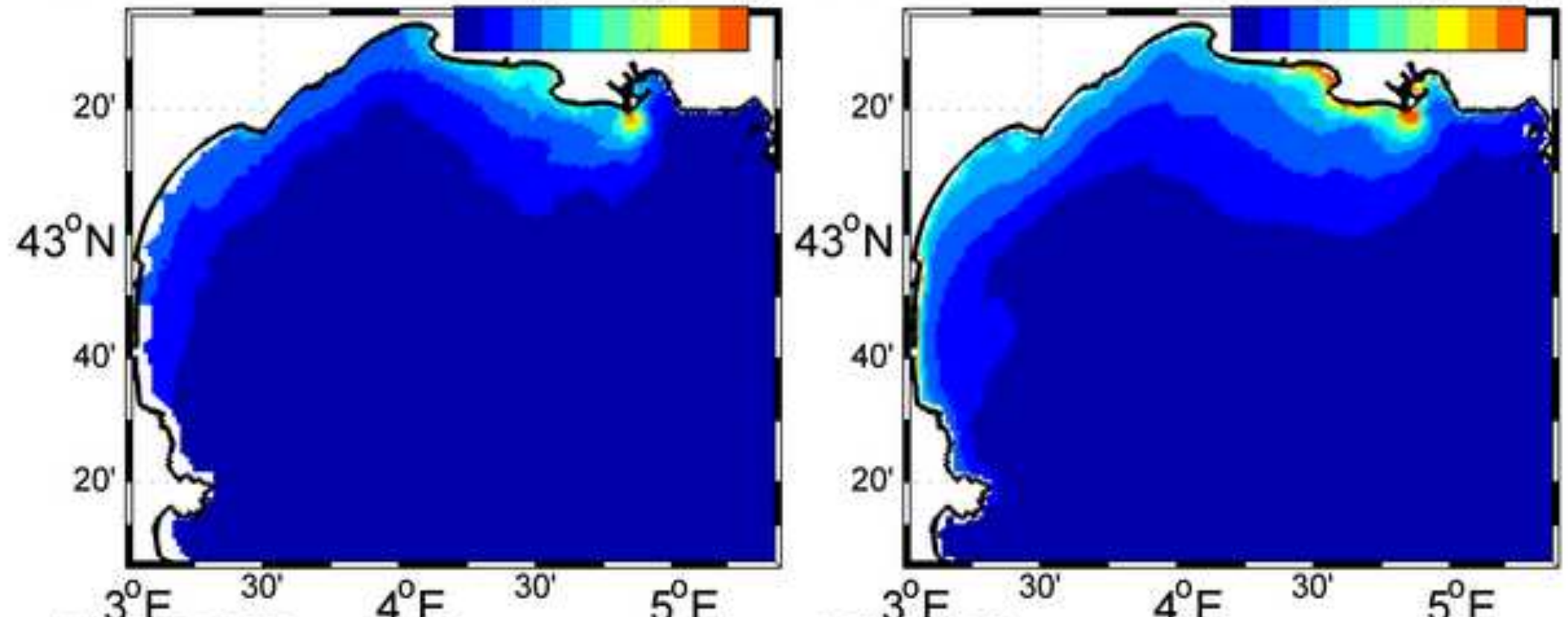

(c) CŌR (\%)
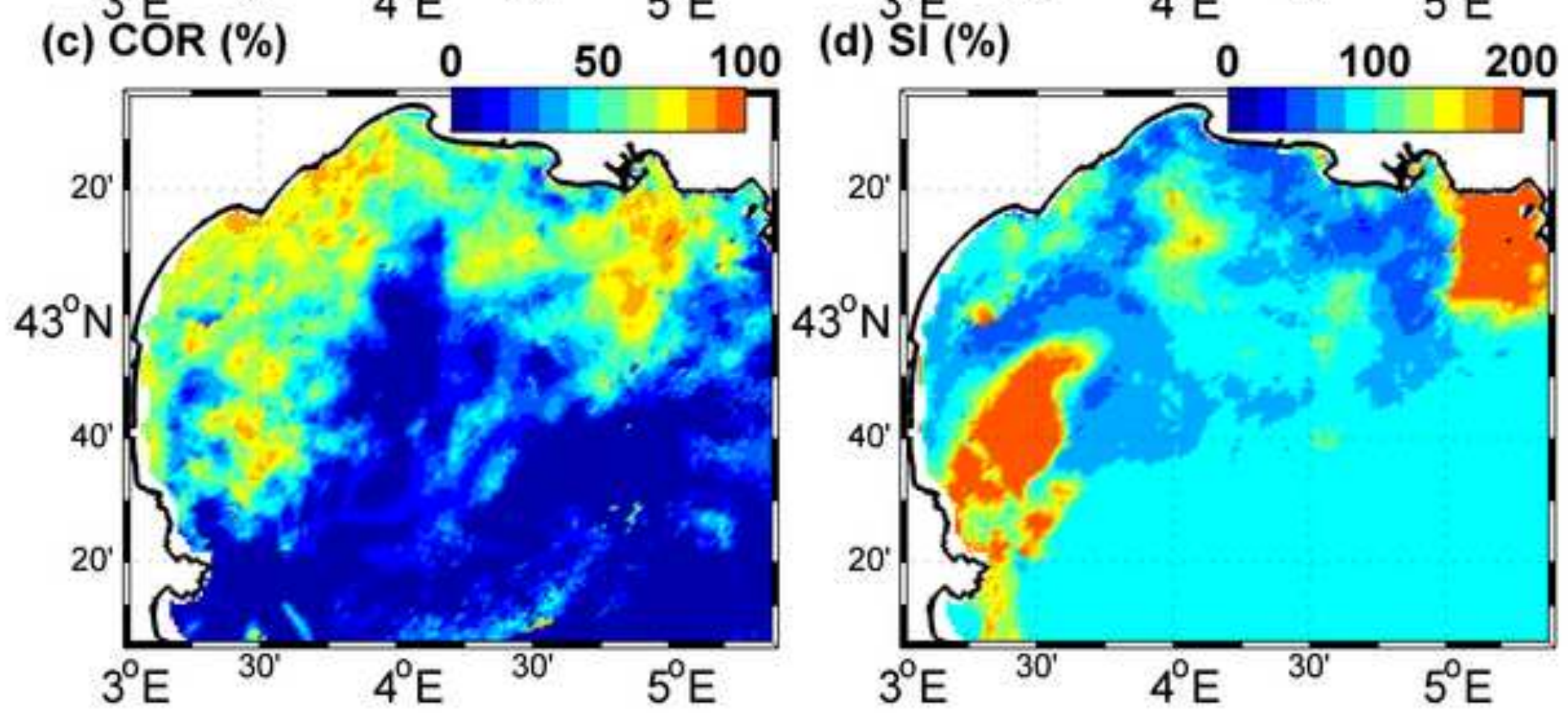

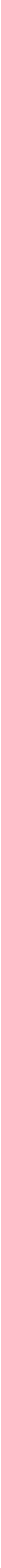


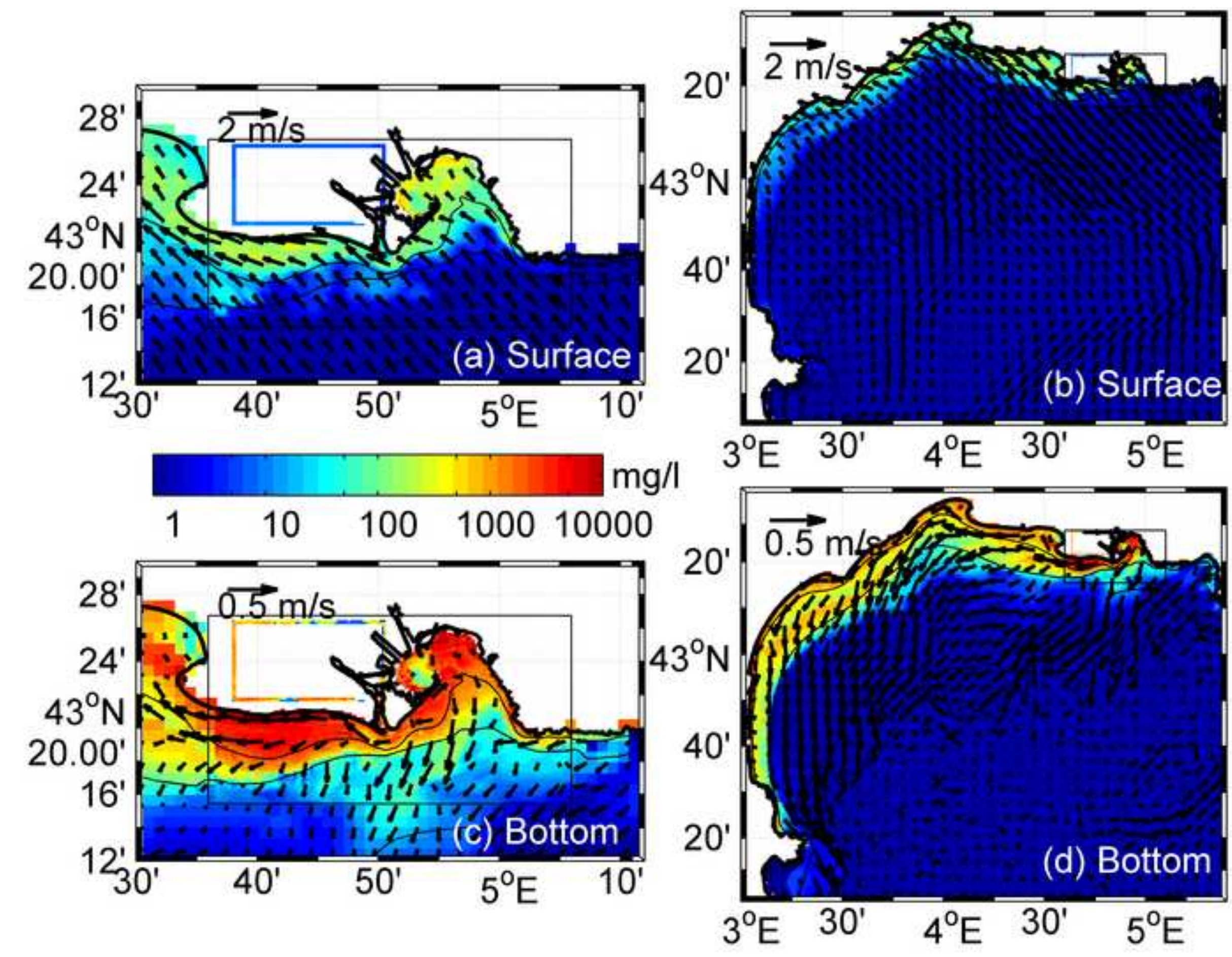




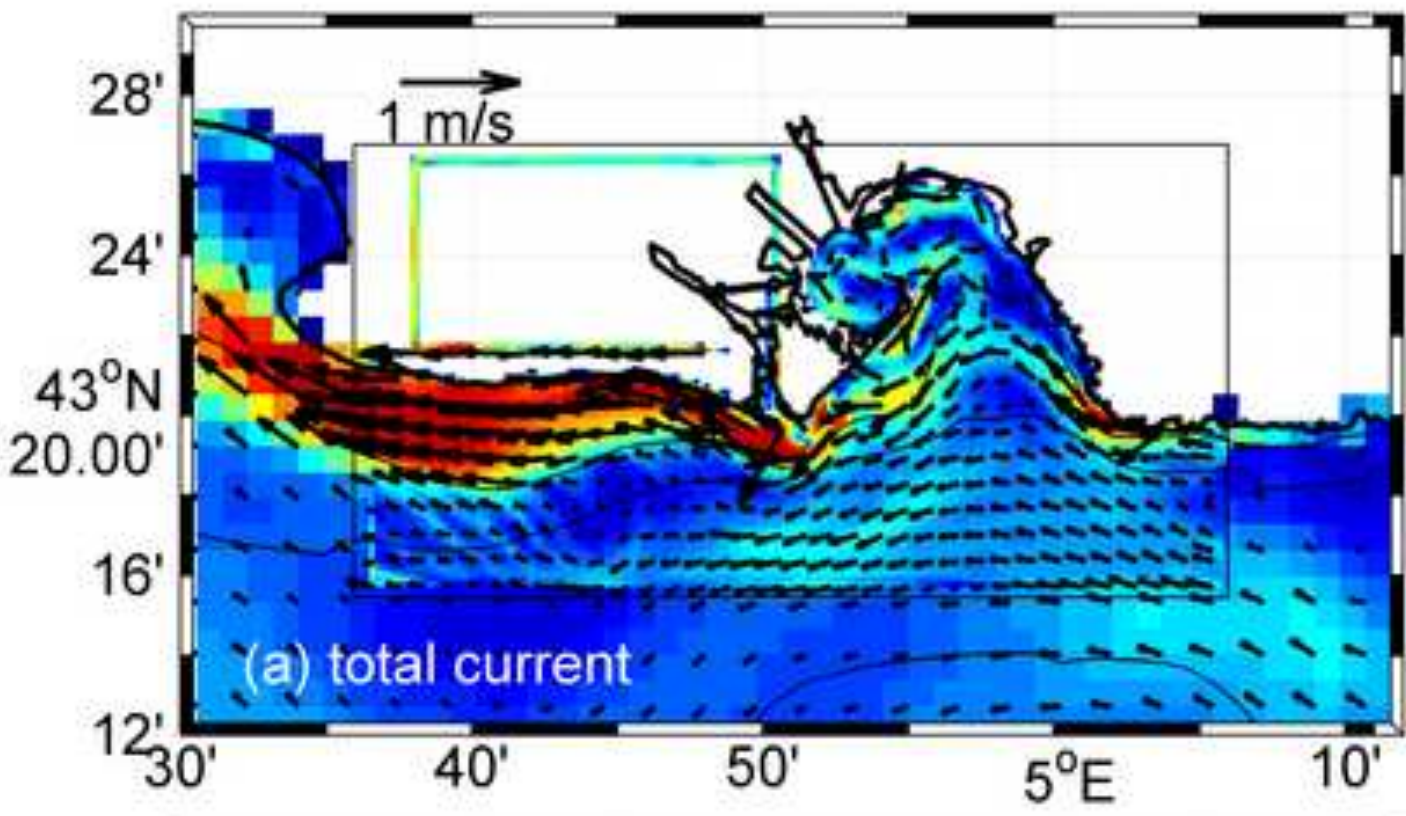

0.6

0.5

0.4

0.3

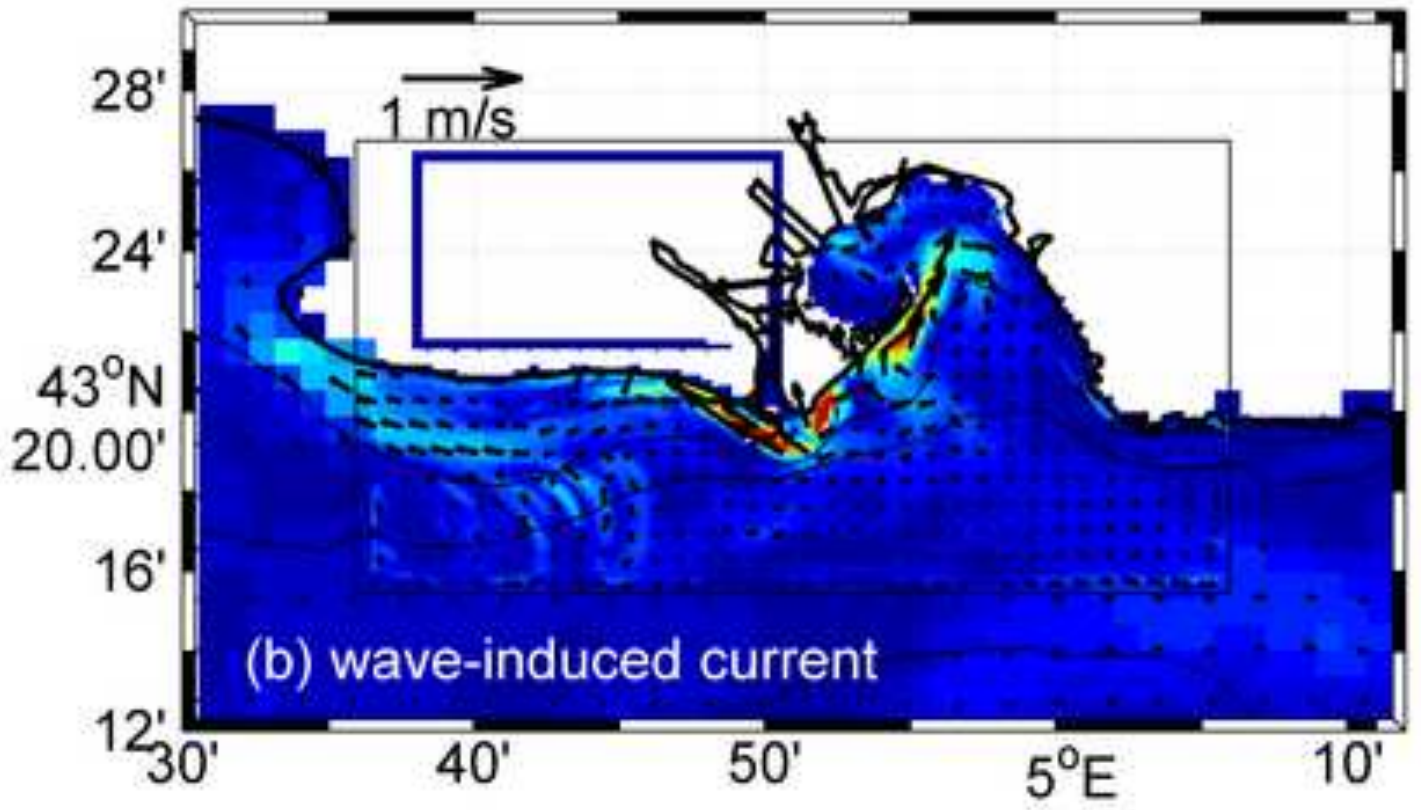

0.2

0.1 


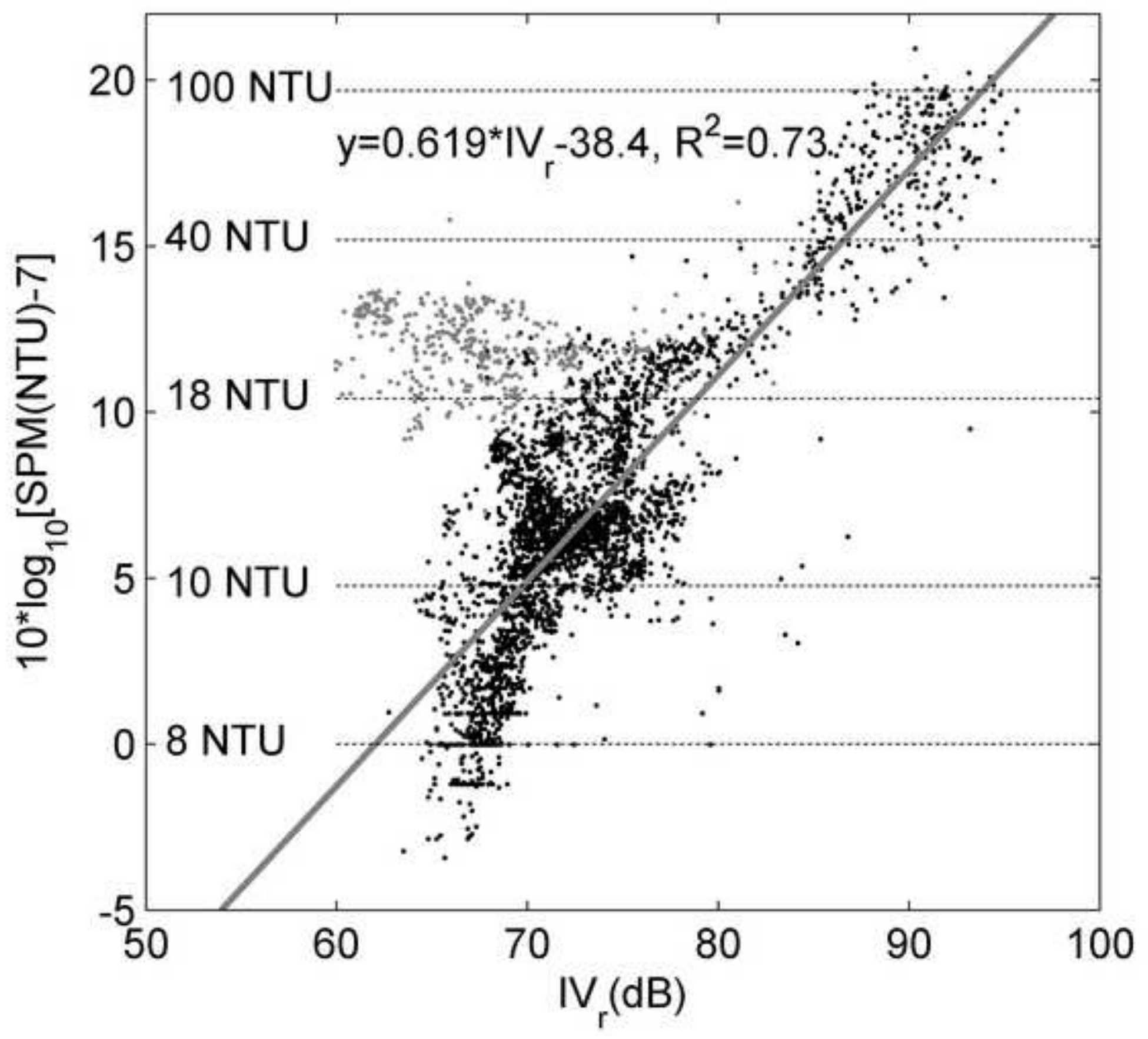




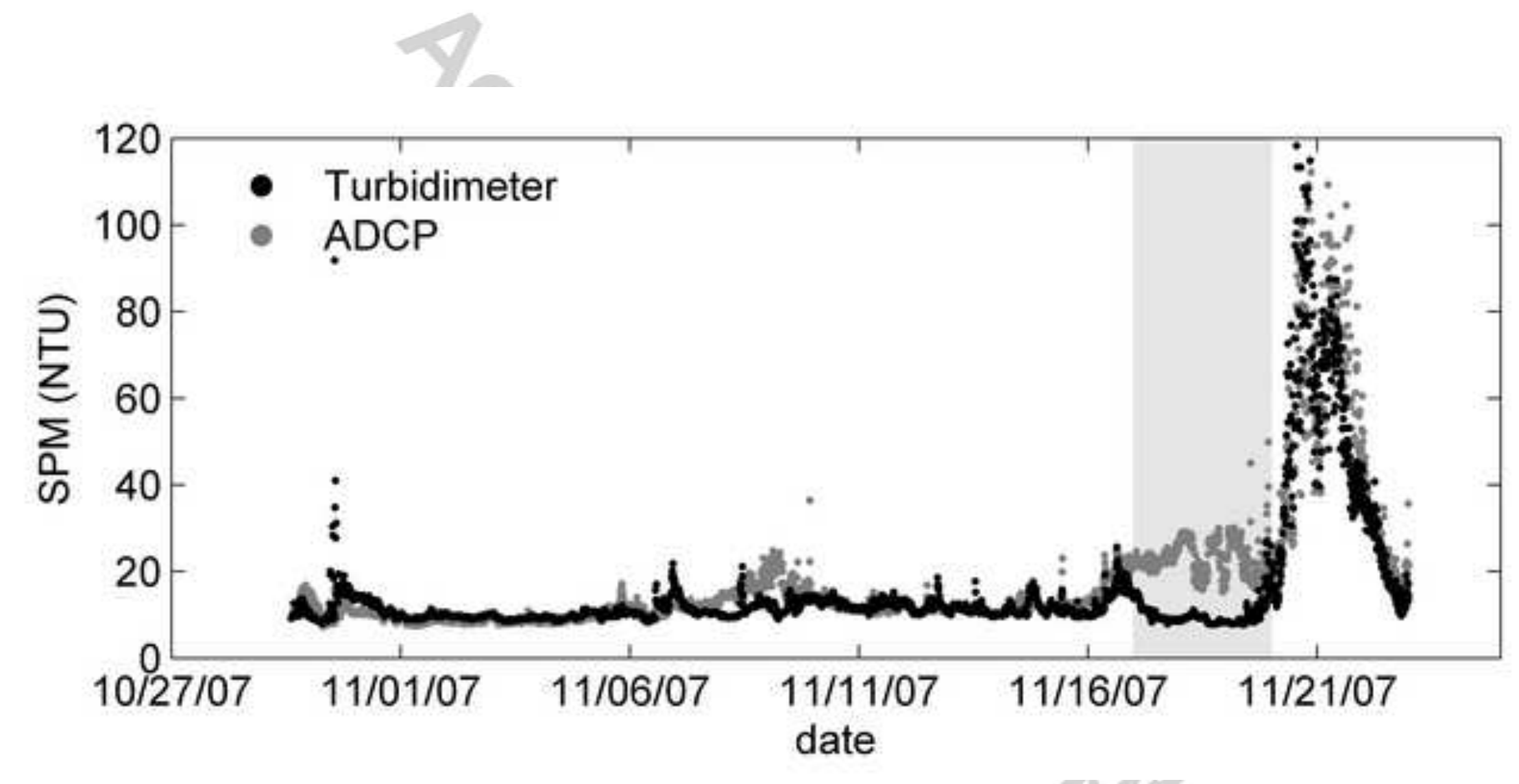

